\title{
Provider Impacts of Socioeconomic Risk Screening and Referral Programs: A Scoping Review
}

\author{
Andrea Quiñones-Rivera, MD, MPH, Holly E. Wing, MA, Jill Barr-Walker, MS, MPH, \\ Megan Yee, BA, Jessica M. Harrison, PhD(c), LCSW, and Laura M. Gottlieb, MD, MPH
}

Background: Initiatives to identify and intervene on patients' socioeconomic needs in the context of health care delivery are expanding. Little information has been compiled across studies on health care providers' knowledge, attitudes, beliefs, and behaviors (KABB) regarding socioeconomic risk screening and referral interventions.

Methods: We conducted a systematic scoping review of providers' KABB related to health care-based socioeconomic risk screening and referral interventions using several search engines. Included studies assessed health care providers' KABB about screening and interventions conducted in clinical settings.

Results: Of 14,757 studies evaluated, 53 were eligible for inclusion. Study designs were heterogeneous. Outcome measures included attitudes and beliefs $(n=42)$, provider behaviors $(n=35)$, and provider knowledge $(n=26)$. The majority of providers expressed positive attitudes toward addressing patients' socioeconomic risks. Participants endorsed concerns regarding insufficient knowledge and resources, time and workflow disruption, and potential negative impacts of screening and referral programs on relationships. Exposure to screening and referral programs led to increases in providers' positive attitudes, socioeconomic risk screening rates, and reported knowledge about intervention options.

Conclusions: Participation in screening and referral programs seems to influence providers' perception of implementation barriers. Future research should explore providers' concerns about addressing identified risks. (J Am Board Fam Med 2021;34:820-831.)

Keywords: Attitude of Health Personnel, Outcome Measures, Referral and Consultation, Scoping Review, Social Determinants of Health, Social Support, Socioeconomic Factors

\section{Introduction}

Strong and consistent evidence has demonstrated that social determinants of health (SDoH) - including socioeconomic factors such as food availability, transportation, income, and housing-are associated with health and well-being. ${ }^{1-12}$ These associations have spurred innovative clinical practices and

This article was externally peer reviewed.

Submitted 28 January 2021; revised 31 March 2021; accepted 14 April 2021.

From LAC-USC Department of Emergency Medicine, Los Angeles, CA (AQR); Center for Health and Community, University of California, San Francisco (HEW, LMG); ZSFG Library, University of California, San Francisco (JBW); Medical College of Wisconsin, Milwaukee (MY); Department of Social and Behavioral Sciences, University of California, San Francisco (JMH); Department of Family and Community Medicine, University of California, San Francisco (LMG).

Conflict of interest: Support for this research was provided by Kaiser Foundation Health Plan Inc. The study sponsor did not play a role in study design; collection, analysis, and interpretation of data; writing the report; and the decision to submit the report for publication. payment models that incentivize intervening on social adversity to improve health outcomes, reduce health spending, and achieve health equity. ${ }^{13,14}$ As described in a recent National Academies of Sciences, Engineering, and Medicine report, these health carebased "social care" practices are diverse and include initiatives that involve detecting patients' social needs and intervening through referrals to community and government-based programs. ${ }^{14}$ Evidence is growing

Financial disclosures: AQR has no financial disclosures; HEW has no financial disclosures; JBW has no financial disclosures; MY has no financial disclosures; JMH has no financial disclosures; LMG has grants from Commonwealth Fund, Robert Wood Johnson Foundation, Episcopal Health Foundation, AHRQ, Kaiser Permanente, and NIMHD. LMG also has current contracts with Mathematica, RTI, and NORC, and previously with the Institute for Healthcare Improvement.

Corresponding author: Laura M. Gottlieb, MD, MPH, University of California, San Francisco, 3333 California Street, Suite 465, San Francisco, CA 94118 (E-mail: Laura. Gottlieb@ucsf.edu). 
that these socioeconomic risk screening and referral programs (screening and referral programs) can contribute to improved health and reduced health care costs. ${ }^{15-19}$

As the effectiveness evidence evolves, a crop of new studies has emerged exploring health care providers' perceptions of both the need for and capacity to implement screening and referral programs. Understanding the provider impacts of these activities is foundational to program implementation and sustainability and should be weighed alongside other elements of the Quadruple Aim. ${ }^{20}$ We conducted a scoping review to summarize this new body of research on health care providers' knowledge, attitudes and beliefs, and behaviors (KABB) about screening and referral programs.

\section{Methods}

This review was guided by existing methodological frameworks and reporting guidelines for scoping reviews. ${ }^{21-23}$ This approach encourages researchers to broadly summarize an emerging field and identify gaps in the literature. Given the breadth of study types and in accordance with scoping review methodology, we did not assess the quality of included studies. ${ }^{21,22}$

\section{Search Strategy}

We employed a 4-step search strategy for identifying relevant studies. First, we conducted a preliminary search of PubMed to identify key articles on our topic and begin the process of term harvesting. From 20 key articles, we extracted text words and Medical Subject Headings (MeSH terms) from titles and abstracts to build a list of keywords and controlled vocabulary terms to create our search strategy. Next, we worked collaboratively with a medical librarian (JBW) to design and refine our search strategy. Potential search terms were tested by examining the unique results for each term to determine relevance to socioeconomic risks and inclusion in the search. Some concepts that were excluded in this way were violence and non-USbased studies, while concepts like literacy and social isolation were included. Third, we searched the evidence library of the University of California, San Francisco Social Interventions Research and Evaluation Network (SIREN), a curated online database of social interventions research. Finally, we searched the reference lists of included articles to identify additional studies and developed search alerts for academic databases to capture similar articles.

The search strategy was developed in PubMed and adapted to other databases using controlled vocabulary (eg, MeSH, Emtree, and thesaurus terms) where available. A second librarian completed a peer review of the final search strategy using the Peer Review of Electronic Search Strategies (PRESS) guidelines. ${ }^{24}$ Scoping reviews are not included in the Prospero database, and therefore this review was not registered.

The final search strategy combined 4 concepts: $\mathrm{SDoH}$, health care providers, interventions, and attitudes. Boolean logic was applied by combining similar keywords and controlled vocabulary by using OR and by using AND between each concept. For example, ("social determinants" OR "food insecurity") AND ("physician” OR "social worker"). To ensure that our search covered the range of interventions related to $\mathrm{SDoH}$, we included broad search terms. No date or language limits were used in the final search. The original database search was conducted in PubMed, Embase, Web of Science, and PsycINFO on January 9, 2018 and then updated on January 29, 2019. The SIREN evidence library was searched on January 29, 2019 and again June 15, 2019 using the preset filter "provider outcome." These additional searches captured relevant articles published through June 15, 2019. The complete search strategy for all databases can be found in Appendix 1.

\section{Study Selection}

Two reviewers (MY, AQR) independently screened a random sample of 200 studies and collaboratively reviewed screening decisions to ensure inter-rater reliability. Reviewers then divided and screened studies based on title and abstract to determine if they met the inclusion criteria for full-text review. Articles that were classified as "maybe" relevant at this stage were then double-screened by the entire review team (MY, AQR, HW, JH). Final screening was completed by the same 4 reviewers. Full texts of each article were reviewed for inclusion by at least 2 authors, and discrepancies were resolved by discussion between the review team. Eligible studies described health care providers' skills, knowledge, attitudes, or behaviors around identifying or addressing patients' socioeconomic risk factors (eg, food insecurity, unstable housing, transportation, 
etc.) in clinical health care delivery systems. Studies evaluating screening and/or intervention activities that did not take place in a clinical setting were excluded. Studies also were excluded if they were not available in English, primary research, peer reviewed, or United States based. Studies focused on adverse childhood events, intimate partner violence, and interpersonal violence without referencing other socioeconomic risk factors were excluded.

\section{Data Extraction and Synthesis}

A standardized data extraction form was developed to catalog information on (1) study setting, (2) study type and methodology, (3) characteristics of the intervention (eg, intervention type, duration, and outcome measures), (4) study population (provider type), (5) socioeconomic risk factor focus, and (6) provider outcomes. Three reviewers (MY, AQR, JH) completed all data extraction activities. Studies fell into 2 groups: those assessing providers' KABB in the context of a screening and referral program and those outside the context of a specific program. Provider outcomes were subdivided into 3 categories: attitudes and beliefs, knowledge, and behaviors.

\section{Results}

The initial literature search yielded 19,417 articles. The search update in January 2019 contributed 2,103 additional studies. After excluding duplicates, 14,742 studies were screened for inclusion based on title and abstract. A total of 15 additional studies were identified through searches of the SIREN database. The full texts of 385 studies were assessed for eligibility, and 332 studies were eliminated based on previously established exclusion criteria. Fifty-three studies were included in the final analysis as indicated in the PRISMA chart (Figure 1). Thirty-six of the 53 studies took place in the context of a screening and referral program. These studies are referred to as intervention-related studies. ${ }^{25-60}$ Thirteen of the intervention-related studies included substantial provider-focused education and training components. $^{30-32,36-38,42-47,57}$ Across the studies, providers' $\mathrm{KABB}$ were assessed using a diverse range of tools, including surveys, interviews, focus groups, and medical record reviews. Intervention study designs included 3 randomized controlled trials (RCTs), ${ }^{25-27} 7$ quasi-experimental designs with comparison groups, ${ }^{28-32,43,44}$ and 26 quasi-experimental designs without control groups (including studies with no preintervention data, as well as studies with both preintervention and postintervention data). ${ }^{33-42,45-60}$ Seventeen studies were conducted outside the context of a specific screening and referral program and instead presented results from surveys more generally exploring providers' attitudes and behaviors about addressing patients' social needs in clinical settings. We refer to these as nonintervention studies. ${ }^{61-77}$ Descriptions of all included studies are available in Appendix Table 1.

The heterogeneity of methods, interventions, settings, targeted populations, and socioeconomic domains across the included studies limited study comparisons (see Table 1). The majority of studies explored providers' KABB related to multidomain social risk screening and referral initiatives, though some focused specifically on 1 social need, eg, food security. Thirty studies (56\%) assessed KABB of physicians who had completed medical school and residency training; 21 (40\%) included residents; 16 $(30 \%)$ included registered nurses and/or nurse practitioners; 6 (11\%) included medical students. Sample sizes ranged widely across included studies ( $\mathrm{n}=6$ to $\mathrm{n}=1298)$.

Both intervention and nonintervention studies assessed a range of outcomes regarding providers' $\mathrm{KABB}$ about integrating screening and referral programs into clinical care. Forty-nine percent included outcomes related to providers' knowledge $(\mathrm{n}=26)$. Attitudes and beliefs were the most commonly reported outcomes $(79 \%, \mathrm{n}=42)$, including measures related to the acceptability of specific interventions and perceived challenges to implementing screening and referral programs in health care delivery contexts. Providers' behaviors were described in $66 \%(n=35)$. The range of outcomes included in the full sample of included articles is listed in Table 2.

\section{Provider Knowledge}

Multiple intervention-related and nonintervention studies assessed provider knowledge. Topics such as knowledge about the prevalence of social needs within the served population, impacts of social needs on health, and resources to address social needs were included. ${ }^{25,27,30,32,35,36,38,41-47,55-57,59,63,64,68-72,75}$ Provider level of knowledge around these topics varied. The most consistent gap in knowledge was about tools and resources needed to address socioeconomic needs once identified. ${ }^{43,55,56,59,64,69}$ One study 
Figure 1. PRISMA flow diagram of included studies in the review. Abbreviation: PRISMA, Preferred Reporting Items for Systematic Reviews and Meta-Analyses.

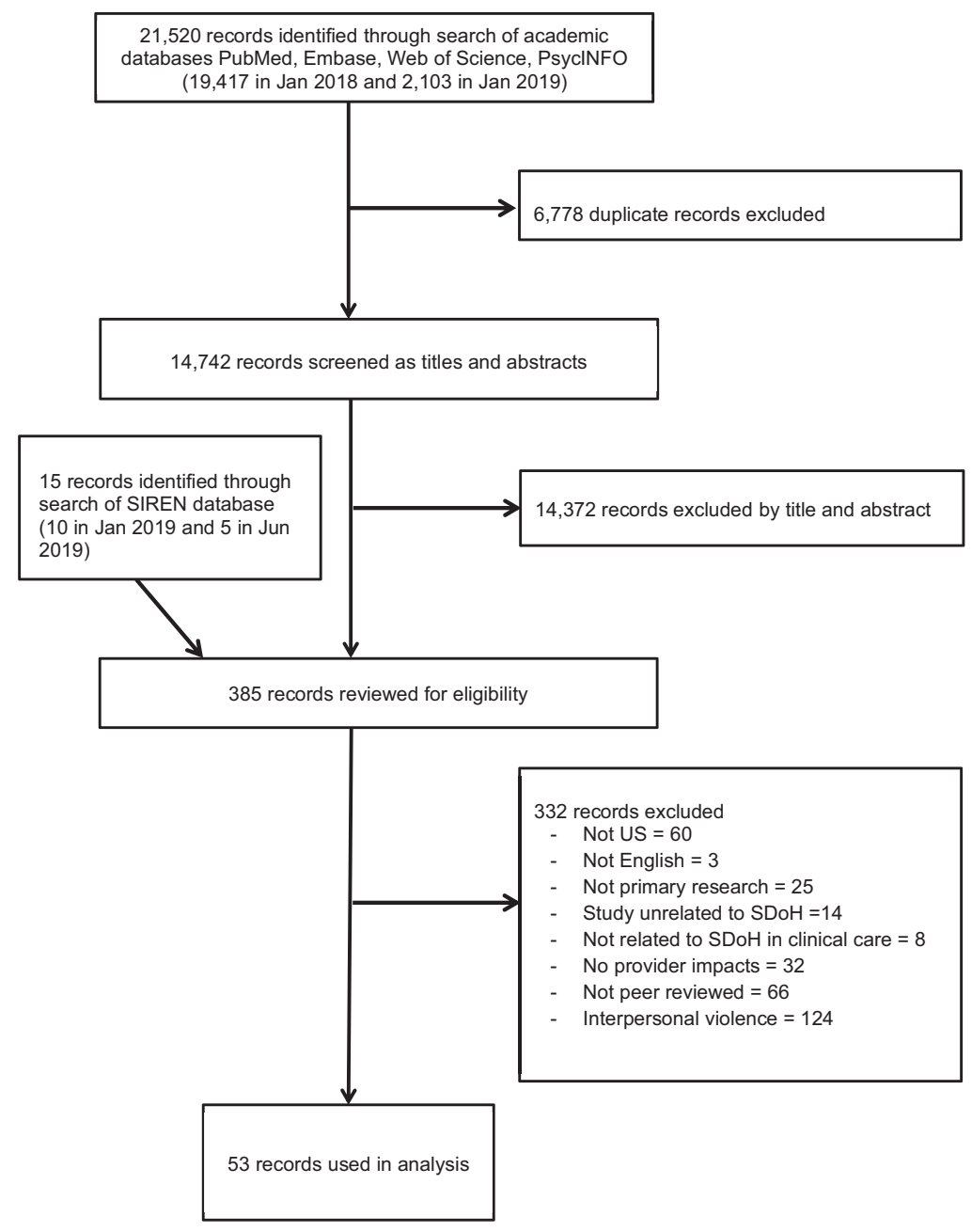

showed that nonphysician respondents $(\mathrm{n}=104)$ were more likely than physician respondents $(\mathrm{n}=$ $154)$ to be aware of relevant socioeconomic resources $(64 \% \text { vs } 45 \%)^{75}$

\section{Impact of Interventions on Provider Knowledge}

The majority of studies examining the impacts of provider education and training about screening and referral programs reported improvements in provider knowledge about socioeconomic needs, including increases in knowledge about identifying and intervening on these needs in clinical care settings. ${ }^{27,30,43-46}$

\section{Provider Attitudes and Beliefs}

Nine nonintervention studies assessed providers' global attitudes about identifying and intervening on patients' social needs in health care contexts. ${ }^{61-63,67-70,72,73}$ Three additional studies assessed providers' attitudes before implementation of a program/intervention. ${ }^{30,45,46}$ Across these 12 studies, the majority of respondents reported believing that patients' socioeconomic needs have significant impacts on health. Respondents endorsed "the importance of addressing social needs" ${ }^{\prime 1}$ and that knowledge about $\mathrm{SDoH}$ was crucial to developing effective programs for vulnerable populations. ${ }^{62}$ The majority of providers surveyed in the nonintervention studies were willing to conduct screening and reported feeling that screening for socioeconomic risks in health care settings was acceptable. ${ }^{62,67,69,70,72,73,75,76}$ Studies also reported a range of provider comfort and confidence with the practice of screening for socioeconomic risks. $39,43,64,67,68$

Beyond screening, the majority of respondents agreed that intervening on socioeconomic risks is also within their individual and/or collective scope 

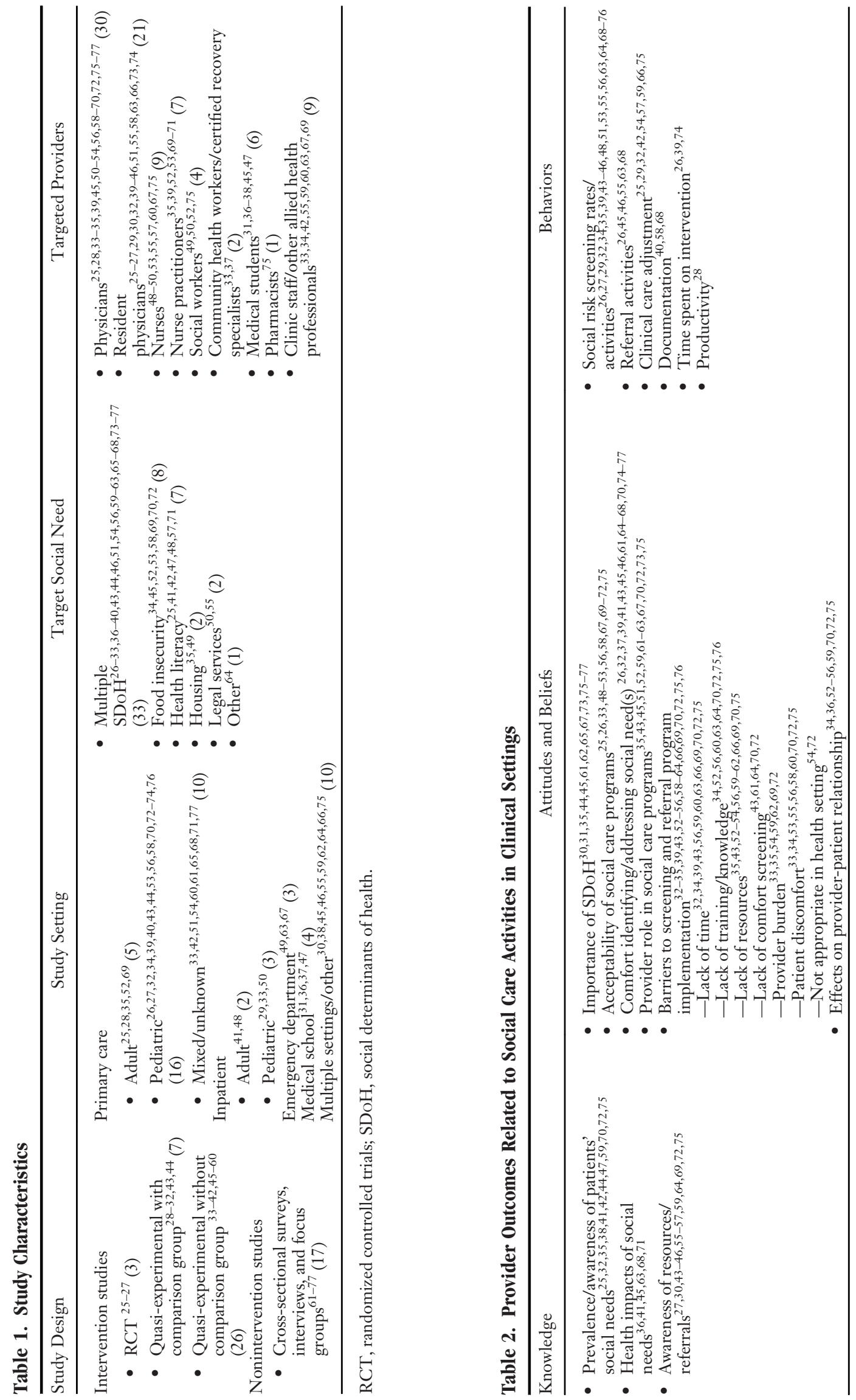

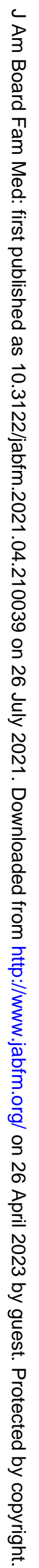


of practice. ${ }^{43,45,59,61-63,67,70,73,75}$ Three studies found significant positive associations between a clinical setting's ability to address patients' socioeconomic risks and providers' job satisfaction and perceptions of health care quality. ${ }^{61,65,77}$ In 12 of 15 studies assessing postintervention-only attitudes after program exposure, the majority of providers endorsed positive attitudes about the specific intervention in which they participated or screening and referral programs generally. ${ }^{33,35,37,38,48-53,56,58}$ Measures reflecting attitudes included topics such as acceptability of screening, process measures (eg, compatibility with clinic flow, screening ease), effect of the program on patient care, and provider satisfaction with the program. Providers in 2 post-only studies primarily expressed hesitation with utility to patient care. ${ }^{34,54}$ In 5 of 15 post-only studies, providers endorsed an increase in their positive attitudes toward screening and referral programs. ${ }^{37,50,51,53,56}$

Ten studies compared pre vs post or comparison vs control group provider attitudes. $25,26,30-32,39,43,45,46,55$ In all of these studies, the majority of providers expressed positive attitudes toward their programs and in 8 studies providers' attitudes about their comfort with screening, and perceived barriers to screening and referral programs became more positive following program implementation. ${ }^{30-32,39,43,45,46,55}$

Twenty-two of the 53 studies highlighted providers' concerns about the potential negative consequences of program implementation. Providers' concerns included discomfort with socioeconomic risk screening ${ }^{43,61,64,70,72}$; insufficient time and workflow disruption $^{32,34,35,39,43,56,59,60,62,63,66,69,70,72,75}$; patient discomfort and negative impact on the patient-provider relationship $33,34,53,55,56,58,60,70,72,75$; and insufficient knowledge and resources to adequately address screening results. $34,35,43,52-54,56,59,61-64,66,69,70,72,75,76$

Provider concerns about screening and referral programs arose primarily in either nonintervention studies or the preprogram implementation period. When evaluated postprogram implementation, concerns about the negative consequences in each of these areas generally abated. Concerns generally fell into 4 categories:

Discomfort with screening: Four provider education and training studies examining the impacts of provider training about SDoH generally and/or socioeconomic risk screening, specifically, demonstrated improvements in provider comfort with screening in at least $1 \mathrm{SDoH}$ domain after participating in a screening and referral program. ${ }^{32,43,45,46}$ One of these studies involved providing training on food insecurity to faculty, residents, and medical students and showed significantly increased selfreported knowledge of food insecurity, resources, and willingness to discuss social needs with patients. ${ }^{45}$ Two additional studies used videos and facilitated discussions to model screening; training reduced residents' discomfort with screening. ${ }^{32,43}$ Concerns about time and workflow: After participating in screening and referral programs, providers often characterized their experiences with screening as "not burdensome," "quick," and "time and workflow were not barriers to screening." $26,32,33,39,51-53,56,58,60$ In 1 study of 45 pediatric residents, $75 \%$ of the residents in the experimental group reported that screening forms did not slow down patient visits. ${ }^{26}$ In 3 intervention studies, providers were initially concerned about workflow but were surprised to find that the program had limited impact on their work or was otherwise beneficial, reporting that the time burden was "less than anticipated" or that screening was "worth the time."26,39,56 In 5 studies, providers reported that time remained a concern after program exposure. ${ }^{43,48,54,56,60}$

Concerns about patient-provider relationships: Six studies highlighted preprogram implementation provider concerns that screening activities might negatively impact patient-provider relationships. ${ }^{34,53,55,56,70,72}$ In 5 studies assessing postimplementation attitudes, providers instead indicated that screening enhanced their relationships with patients or did not have a negative impact. ${ }^{33,52-55}$

Addressing socioeconomic risks: Concerns about the availability of resources to address identified risks revolved around providers' (1) desire for more knowledge/confidence on addressing socioeconomic needs; (2) uncertainty regarding the effectiveness of resource lists and referral networks in their interventions; and (3) interest in more systems-level logistic support and material resources. Eight studies documented provider concerns postprogram implementation about the ability to provide adequate resources to address identified socioeconomic needs. ${ }^{34,35,43,52-54,56,59}$ Three studies suggested that providers' confidence around addressing patients' needs increased following program implementation. . $^{39,43,46}$

Attitudes and beliefs about screening and referral programs differed across groups. Several studies found that individual-level provider characteristics such as provider specialty, under-represented in 
medicine (URM) identity, and gender were associated with provider attitudes. One large study $(\mathrm{n}=$ 240 faculty physicians) found that compared with nonminority physicians and specialists, minority physicians and primary care providers (PCPs) were more likely to think that the benefits of collecting patients' socioeconomic risk information outweigh negative consequences (51\% nonminority vs $66 \%$ minority physicians; $54 \%$ specialists vs $78 \%$ PCPs.). ${ }^{62}$ In the same study, all physician groups identified lack of clinic and health system infrastructure to address social needs as the primary barrier to program adoption. The second-most cited concern among nonminority physicians and specialists was uncertainty around what to do with social risk data once collected. Among minority physicians and PCPs, the second-most cited concern was liability related to not addressing an identified risk. ${ }^{62}$ In the same study, female physicians were more likely than other groups to think it was appropriate to include socioeconomic data in electronic health records. ${ }^{62}$

In 1 study with pediatric emergency medicine providers $(n=114)$, a majority of respondents rated screening as important; a higher percentage of nursing staff $(58.1 \%)$ than physicians $(28.2 \%)$ preferred screening to be conducted by physicians. ${ }^{67}$ In 1 nonintervention study ( $\mathrm{n}=258$ providers), time constraints were cited as barriers by $70 \%$ of physicians compared with $47 \%$ of nonphysician providers. ${ }^{75}$ In another study of clinical faculty providers $(n=240), 54 \%$ of physicians agreed that PCPs should be primarily responsible for managing socioeconomic risk factors, but when asked whether they should be solely responsible for addressing needs, significantly more specialists than PCPs agreed. ${ }^{62}$ In 4 studies, providers reported wanting ancillary staff to provide support with screening and referrals. ${ }^{25,51,56,69}$ In 1 large study ( $\left.\mathrm{n}=258\right)$, $94 \%$ of clinicians thought social workers should conduct screening. ${ }^{75}$

\section{Provider Behaviors}

Across nonintervention studies, providers consistently reported screening for a wide range of socioeconomic risks. Reported screening frequency, tools, and approaches varied across these studies, however. Some studies reported that providers screen a pre-established target population (eg, patients with diabetes) while others reported that providers are prompted to screen in response to patient factors (such as comorbid conditions) identified in the context of clinical encounters. ${ }^{69,70}$ Several studies highlighted associations between provider characteristics, practice settings, and provider screening and referral behaviors. Two nonintervention studies found that providers practicing in clinical settings with staff whose role is to connect patients to community resources screened more frequently and referred to more community resources than providers with no or limited on-site resources. ${ }^{74,76}$ One large study of pediatricians ( $\mathrm{n}=$ 602) found that those identifying as female, URM, practicing as generalists, or in rural settings were more likely to routinely conduct screening. ${ }^{76}$ Another study of family practice pediatric physicians and nurse practitioners $(n=186)$ found a negative association with lack of provider time and monitoring for family nutrition, specifically. ${ }^{70}$

\section{Impact of Screening and Referral Programs on Provider Behaviors}

All studies assessing screening rates before and after implementation of a screening and referral program showed statistically significant increases in screening behaviors in at least $1 \mathrm{SDoH}$ domain. ${ }^{26,27,29,32,35,39,40,45,46,56}$ Few studies assessed long-term impacts on screening behavior. In 1 study the "median survival time of increased screening was 8.1 month" 29 ; in another, the screening model continued to be in use 2 years following program implementation, but screening rates were not assessed at follow-up. ${ }^{56}$

\section{Discussion}

In this scoping review, we found a diverse group of studies exploring providers' KABB related to socioeconomic risk screening and referral programs in clinical settings. Thirty-six of these studies took place in the context of specific screening and referral initiatives. Across studies, a majority of clinicians and other clinical staff generally expressed positive attitudes about addressing patients' socioeconomic needs in health care settings. Three studies in this review described significant associations between the clinical setting's capacity to address patients' socioeconomic needs and providers' sense of professional satisfaction. ${ }^{61,65,77}$

In studies conducted outside the context of a screening and referral program $(\mathrm{n}=17)$, providers 
expressed more concerns about the potential negative consequences of program adoption. In contrast, providers exposed to these programs more consistently reported positive impacts on patient-provider relationships, increased comfort with screening and referral practices, and fewer concerns about clinic workflow disruption. However, even in the context of program exposure, concerns persisted about capacity to adequately address patients' socioeconomic needs. These findings suggest that program exposure may decrease some, but not all, providerrelated barriers to implementation.

Providers' persistent concerns about capacity to adequately address patients' socioeconomic needs should not be overlooked. Existing evidence on the impacts of screening and referral programs is mixed, ${ }^{78}$ though a growing number of studies suggest referrals programs may help to reduce patients' socioeconomic needs and affect health. ${ }^{17,79-83}$ No studies in this review, however, described a program in which providers track patient outcomes postreferral, which may contribute to providers' persistent concerns about the adequacy of their referrals. In parallel, providers' focus on intervention effectiveness should be considered alongside studies in this field that have reported patients' perspectives on screening and referral programs. These studies suggest that patients value the patient-provider rapport building that develops from discussions about socioeconomic needs regardless of the social services referrals provided. ${ }^{27,84-86}$ This inconsistency between provider and patient expectations warrants more attention in provider training and education. If providers are more aware of patients' expectations, they may better understand the value of these programs beyond referrals to social services.

Findings from studies undertaken in the context of screening and referral programs strongly suggested that provider education and training initiatives can impact provider behaviors and attitudes; such programs consistently reported post-training increases in socioeconomic risk screening and referral rates. However, most of these studies assessed these behavior changes over relatively short periods (max 12 to 18 months). Characterizing core training components and assessing more longitudinal outcomes are important areas for future research. This research would be facilitated by consensus on tools that gauge providers' KABB in this area.
Interestingly, 9 of the 13 studies that included provider education and training focused on physicians or physician trainees. ${ }^{30-32,36,43-47}$ Improving physician education on these topics is a growing focus in undergraduate and postgraduate medical education. ${ }^{87,88}$ Given the multidisciplinary workforce involved in many screening and referral programs, however, more attention should focus on meeting the training needs-and assessing the impacts of training — of a more diverse workforce. ${ }^{14,89}$

\section{Limitations}

There are 4 important limitations to consider in interpreting our findings. First, we narrowly focused on provider outcomes associated with socioeconomic risk screening and referral programs. This excludes health care activities that might address other social and structural determinants of health and equity, including racism. Future reviews will need to explore the impacts of programs aimed at addressing these other drivers on patients, population health, and clinical settings. Second, study abstracts that did not refer to provider outcomes were excluded. This may have limited our ability to identify relevant studies. Third, the review reflects a wide variety of different studies, many of which assessed provider attitudes via surveys, which are likely influenced by multiple forms of bias. Qualitative work and chart-based studies could more comprehensively explore changes in KABB. Finally, study heterogeneity-including different types of socioeconomic risk screening conductedand lack of standardized outcome measures limited our ability to draw comparisons across studies. In addition, while a critical appraisal of the studies was not included in this review, many included studies were of nonexperimental designs.

\section{Conclusions}

In this systematic scoping review, we identified a wide range of studies that describe providers' KABB related to health care-based socioeconomic risk screening and referral programs. Study contexts influenced providers' concerns about program adoption: providers not participating in these programs were more likely than providers participating in such programs to report significant feasibility and implementation barriers. Rigorously conducted studies involving both clinicians and ancillary staff 
members involved in screening and referral initiatives will help to identify both implementation barriers and strategies to overcome them. Future studies also should clarify training required to ensure professional competence related to social and medical care integration.

The authors gratefully acknowledge the contribution of Dylnne Gonzalez in editing the manuscript.

To see this article online, please go to: bttp://jabfm.org/content/ 33/5/820.full.

\section{References}

1. Braveman P, Egerter S, Williams DR. The social determinants of health: coming of age. Annu Rev Public Health 2011;32:381-98.

2. Marmot M, Bell R. Fair society, healthy lives. Public Health 2012;126:S4-S10.

3. Adler NE, Stewart J. Preface to the biology of disadvantage: socioeconomic status and health. Ann NY Acad Sci 2010;1186:1-4.

4. Larson K, Halfon N. Family income gradients in the health and health care access of US children. Matern Child Health J 2010;14:332-42.

5. Victorino CC, Gauthier AH. The social determinants of child health: variations across health outcomes - a population-based cross-sectional analysis. BMC Pediatr 2009;9:53.

6. Kaplan GA, Shema SJ, Leite CM. Socioeconomic determinants of psychological well-being: the role of income, income change, and income sources during the course of 29 years. Ann Epidemiol 2008;18:531-7.

7. Koch CG, Li L, Kaplan GA, et al. Socioeconomic position, not race, is linked to death after cardiac surgery. Circ Cardiovasc Qual Outcomes 2010; 3:267-76.

8. Weinreb L, Wehler C, Perloff J, et al. Hunger: its impact on children's health and mental health. Pediatrics 2002;110:e41.

9. Kondo N. Socioeconomic disparities and health: impacts and pathways. J Epidemiol 2012;22:2-6.

10. Socioeconomic status and health in industrial nations: social, psychological, and biological pathways. Ann N Y Acad Sci 1999;896:1-503.

11. Marmot M. Social determinants of health inequalities. Lancet 2005;365:1099-104.

12. Cutts DB, Meyers AF, Black MM, et al. US housing insecurity and the health of very young children. Am J Public Health 2011;101:1508-14.

13. Arnett DK, Blumenthal RS, Albert MA, et al. 2019 ACC/AHA guideline on the primary prevention of cardiovascular disease: a report of the American College of Cardiology/American Heart Association
Task Force on Clinical Practice Guidelines. Circulation 2019;140:e596-e646.

14. National Academies of Sciences, Engineering, and Medicine. Integrating social care into the delivery of health care: moving upstream to improve the nation's health. Washington (DC): National Academies Press; 2019.

15. Vasan A, Morgan JW, Mitra N, et al. Effects of a standardized community health worker intervention on hospitalization among disadvantaged patients with multiple chronic conditions: a pooled analysis of three clinical trials. Health Serv Res 2020;55(Suppl 2):894-901.

16. Kangovi S, Mitra N, Grande D, Long JA, Asch DA. Evidence-based community health worker program addresses unmet social needs and generates positive return on investment. Health Aff (Millwood) 2020;39:207-13.

17. Kangovi S, Mitra N, Norton L, et al. Effect of community health worker support on clinical outcomes of low-income patients across primary care facilities: a randomized clinical trial. JAMA Intern Med 2018;178:1635-43.

18. Berkowitz SA, Delahanty LM, Terranova J, et al. Medically tailored meal delivery for diabetes patients with food insecurity: a randomized crossover trial. J Gen Intern Med 2019;34:396-404.

19. Sadowski LS, Kee RA, VanderWeele TJ, Buchanan D. Effect of a housing and case management program on emergency department visits and hospitalizations among chronically ill homeless adults: a randomized trial. JAMA 2009;301:1771-8.

20. Bodenheimer T, Sinsky C. From triple to quadruple aim: care of the patient requires care of the provider. Ann Fam Med 2014;12:573-6.

21. Arksey H, O'Malley L. Scoping studies: towards a methodological framework. Int J Social Research Methodology 2005;8:19-32.

22. Levac D, Colquhoun H, O'Brien KK. Scoping studies: advancing the methodology. Implement Sci 2010;5:69.

23. Tricco AC, Lillie E, Zarin W, et al. PRISMA extension for scoping reviews (PRISMA-ScR): checklist and explanation. Ann Intern Med 2018;169:467-73.

24. McGowan J, Sampson M, Salzwedel DM, Cogo E, Foerster V, Lefebvre C. PRESS Peer Review of Electronic Search Strategies: 2015 guideline statement. J Clin Epidemiol 2016;75:40-6.

25. Seligman HK, Wang FF, Palacios JL, et al. Physician notification of their diabetes patients' limited health literacy: a randomized, controlled trial: erratum. J Gen Intern Med 2005;20:1077.

26. Garg A, Butz AM, Dworkin PH, Lewis RA, Thompson RE, Serwint JR. Improving the management of family psychosocial problems at low-income 
children's well-child care visits: the WE CARE Project. Pediatrics 2007;120:547-58.

27. Feigelman S, Dubowitz H, Lane W, Grube L, Kim J. Training pediatric residents in a primary care clinic to help address psychosocial problems and prevent child maltreatment. Acad Pediatr 2011; 11:474-80.

28. Dorr DA, Wilcox A, McConnell KJ, Burns L, Brunker CP. Productivity enhancement for primary care providers using multicondition care management. Am J Manag Care 2007;13:22-8.

29. Colvin JD, Bettenhausen JL, Anderson-Carpenter $\mathrm{KD}$, et al. Multiple behavior change intervention to improve detection of unmet social needs and resulting resource referrals. Acad Pediatr 2016; 16:168-74.

30. Kuo AA, Shetgiri R, Guerrero AD, et al. A public health approach to pediatric residency education: responding to social determinants of health. J Grad Med Educ 2011;3:217-23.

31. Girotti JA, Loy GL, Michel JL, Henderson VA. The urban medicine program: developing physician-leaders to serve underserved urban communities. Acad Med 2015;90:1658-66.

32. O’Toole JK, Solan LG, Burkhardt MC, Klein MD. Watch and learn: an innovative video trigger curriculum to increase resident screening for social determinants of health. Clin Pediatr (Phila) 2013; $52: 344-50$.

33. Sundar KR. Universal screening for social needs in a primary care clinic: a quality improvement approach using the Your Current Life Situation Survey. Perm J 2018;22:18-89.

34. Knowles M, Khan S, Palakshappa D, et al. Successes, challenges, and considerations for integrating referral into food insecurity screening in pediatric settings. J Health Care Poor Underserved 2018;29:181-91.

35. Chhabra M, Sorrentino AE, Cusack M, Dichter ME, Montgomery AE, True G. Screening for housing instability: providers' reflections on addressing a social determinant of health. J Gen Intern Med 2019;34:1213-9.

36. Onyekere C, Ross S, Namba A, Ross JC, Mann BD. Medical student volunteerism addresses patients' social needs: a novel approach to patient-centered care. Ochsner J 2016;16:45-9.

37. Kangovi S, Carter T, Smith RA, DeLisser HM. A community health worker-led rotation to train medical students in the social determinants of health. J Health Care Poor Underserved 2018;29: 581-90.

38. O'Brien MJ, Garland JM, Murphy KM, Shuman SJ, Whitaker RC, Larson SC. Training medical students in the social determinants of health: the Health Scholars Program at Puentes de Salud. Adv Med Educ Pract 2014;5:307-14.
39. Zielinski S, Paradis HA, Herendeen P, Barbel P. The identification of psychosocial risk factors associated with child neglect using the WE-CARE Screening Tool in a high-risk population. Erratum. J Pediatric Health Care 2018;32:211.

40. Patel M, Bathory E, Scholnick J, White-Davis T, Choi J, Braganza S. Resident documentation of social determinants of health: effects of a teaching tool in the outpatient setting. Clin Pediatr (Phila) 2018;57:451-6.

41. Wahab A, Ali A, Nazir S, et al. A QI initiative for bridging the health literacy gap by educating internal medicine residents at a community hospital. J Community Hospital Internal Medicine Perspectives 2018;8:260-6.

42. Coleman CA, Fromer A. A health literacy training intervention for physicians and other health professionals. Fam Med 2015;47:388-92.

43. Klein MD, Alcamo AM, Beck AF, et al. Can a video curriculum on the social determinants of health affect residents' practice and families' perceptions of care? Acad Pediatr 2014;14:159-66.

44. Klein MD, Kahn RS, Baker RC, Fink EE, Parrish DS, White DC. Training in social determinants of health in primary care: does it change resident behavior? Acad Pediatr 2011;11:387-93.

45. Smith S, Malinak D, Chang J, Schultz A, Brownell $\mathrm{K}$. Addressing food insecurity in family medicine and medical education. Fam Med 2017;49:765-71.

46. Real FJ, Beck AF, Spaulding JR, Sucharew H, Klein MD. Impact of a neighborhood-based curriculum on the helpfulness of pediatric residents' anticipatory guidance to impoverished families. Matern Child Health J 2016;20:2261-7.

47. Primack BA, Bui T, Fertman CI. Social marketing meets health literacy: innovative improvement of health care providers' comfort with patient interaction. Patient Educ Couns 2007;68:3-9.

48. Sand-Jecklin K, Daniels CS, Lucke-Wold N. Incorporating health literacy screening into patients' health assessment. Clin Nurs Res 2017; 26:176-90.

49. Gabrielian S, Chen JC, Minhaj BP, et al. Feasibility and acceptability of a colocated homeless-tailored primary care clinic and emergency department. J Prim Care Community Health 2017;8:338-44.

50. Pettignano R, Caley SB, McLaren S. The health law partnership: adding a lawyer to the health care team reduces system costs and improves provider satisfaction. J Public Health Manag Pract 2012;18: E1-3.

51. Page-Reeves J, Kaufman W, Bleecker $M$, et al. Addressing social determinants of health in a clinic setting: the WellRx pilot in Albuquerque, New Mexico. J Am Board Fam Med 2016;29:414-8.

52. O’Toole TP, Roberts CB, Johnson EE. Screening for food insecurity in six Veterans Administration 
clinics for the homeless, June-December 2015. Prev Chronic Dis 2017;14.

53. Palakshappa D, Vasan A, Khan S, Seifu L, Feudtner C, Fiks AG. Clinicians' perceptions of screening for food insecurity in suburban pediatric practice. Pediatrics 2017;140:e20170319.

54. Tong ST, Liaw WR, Kashiri PL, et al. Clinician experiences with screening for social needs in primary care. J Am Board Fam Med 2018;31:351-63.

55. Cohen E, Fullerton DF, Retkin R, et al. Medicallegal partnership: collaborating with lawyers to identify and address health disparities. J Gen Intern Med 2010;25:136-9.

56. Eismann EA, Theuerling J, Maguire S, Hente EA, Shapiro RA. Integration of the Safe Environment for Every Kid (SEEK) model across primary care settings. Clin Pediatr (Phila) 2019;58:166-76.

57. Stikes R, Arterberry K, Logsdon MC. A nurse leadership project to improve health literacy on a maternal-infant unit. J Obstet Gynecol Neonatal Nurs 2015;44:665-76.

58. Adams E, Hargunani D, Hoffmann L, Blaschke G, Helm J, Koehler A. Screening for food insecurity in pediatric primary care: a clinic's positive implementation experiences. J Health Care Poor Underserved 2017;28:24-9.

59. Hamity C, Jackson A, Peralta L, Bellows J. Perceptions and experience of patients, staff, and clinicians with social needs assessment. Perm J 2018;22:18-105.

60. Byhoff E, Garg A, Pellicer M, et al. Provider and staff feedback on screening for social and behavioral determinants of health for pediatric patients. J Am Board Fam Med 2019;32:297-306.

61. Olayiwola JN, Willard-Grace R, Dubé K, et al. Higher perceived clinic capacity to address patients' social needs associated with lower burnout in primary care providers. J Health Care Poor Underserved 2018;29:415-29.

62. Palacio A, Seo D, Medina H, Singh V, Suarez M, Tamariz L. Provider perspectives on the collection of social determinants of health. Popul Health Manag 2018;21:501-8.

63. Losonczy LI, Hsieh D, Hahn C, Fahimi J, Alter H. More than just meds: national survey of providers' perceptions of patients' social, economic, environmental, and legal needs and their effect on emergency department utilization. Soc Med 2015;9:22-8.

64. Grindler NM, Allshouse AA, Jungheim E, Powell TL, Jansson T, Polotsky AJ. OBGYN screening for environmental exposures: a call for action. PLoS One 2018;13:e0195375.

65. Pantell MS, De Marchis E, Bueno A, Gottlieb LM. Practice capacity to address patients' social needs and physician satisfaction and perceived quality of care. Ann Fam Med 2019;17:42-5.
66. Purnell TS, Marshall JK, Olorundare I, et al. Provider perceptions of the organization's cultural competence climate and their skills and behaviors targeting patient-centered care for socially at-risk populations. J Health Care Poor Underserved 2018;29:481-96.

67. Robinson T, Bryan L, Johnson V, McFadden T, Lazarus S, Simon HK. Hunger: a missed opportunity for screening in the pediatric emergency department. Clin Pediatr (Phila) 2018;57:1318-25.

68. Lewis JH, Whelihan K, Navarro I, Boyle KR, SDH Card Study Implementation Team. Community health center provider ability to identify, treat and account for the social determinants of health: a card study. BMC Fam Pract 2016;17:121.

69. Pooler JA, Hoffman VA, Karva FJ. Primary care providers' perspectives on screening older adult patients for food insecurity. J Aging Soc Policy 2018;30:1-23.

70. Hoisington AT, Braverman MT, Hargunani DE, Adams EJ, Alto CL. Health care providers' attention to food insecurity in households with children. Prev Med 2012;55:219-22.

71. Cafiero M. Nurse practitioners' knowledge, experience, and intention to use health literacy strategies in clinical practice. J Health Commun 2013;18: 70-81.

72. Barnidge E, LaBarge G, Krupsky K, Arthur J. Screening for food insecurity in pediatric clinical settings: opportunities and barriers. J Community Health 2017;42:51-7.

73. Garg A, Butz AM, Dworkin PH, Lewis RA, Serwint JR. Screening for basic social needs at a medical home for low-income children. Clin Pediatr (Phila) 2009;48:32-6.

74. O’Toole JK, Burkhardt MC, Solan LG, Vaughn L, Klein MD. Resident confidence addressing social history: is it influenced by availability of social and legal resources? Clin Pediatr (Phila) 2012;51:625-31.

75. Schickedanz A, Hamity C, Rogers A, Sharp AL, Jackson A. Clinician experiences and attitudes regarding screening for social determinants of health in a large integrated health system. Med Care 2019;57:S197-S201.

76. Garg A, Cull W, Olson L, et al. Screening and referral for low-income families' social determinants of health by US pediatricians. Acad Pediatr 2019;19:875-83.

77. De Marchis E, Knox M, Hessler D, et al. Physician burnout and higher clinic capacity to address patients' social needs. J Am Board Fam Med 2019;32:69-78.

78. Gottlieb LM, Wing H, Adler NE. A systematic review of interventions on patients' social and economic needs. Am J Prev Med 2017;53:719-29.

79. Gottlieb LM, Hessler D, Long D, et al. Effects of social needs screening and in-person service 
navigation on child health: a randomized clinical trial. JAMA Pediatr 2016;170:e162521.

80. Pantell MS, Hessler D, Long D, et al. Effects of inperson navigation to address family social needs on child health care utilization: a randomized clinical trial. JAMA Netw Open 2020;3:e206445.

81. Gottlieb LM, Adler NE, Wing H, et al. Effects of in-person assistance vs personalized written resources about social services on household social risks and child and caregiver health: a randomized clinical trial. JAMA Netw Open 2020;3:e200701.

82. Berkowitz SA, Hulberg AC, Standish S, Reznor G, Atlas SJ. Addressing unmet basic resource needs as part of chronic cardiometabolic disease management. JAMA Intern Med 2017;177:244-52.

83. Sege R, Preer G, Morton SJ, et al. Medical-legal strategies to improve infant health care: a randomized trial. Pediatrics 2015;136:97-106.

84. Byhoff E, De Marchis EH, Hessler D, et al. Part II: a qualitative study of social risk screening acceptability in patients and caregivers. Am J Prev Med 2019;57:S38-S46.
85. Rogers AJ, Hamity C, Sharp AL, Jackson AH, Schickedanz AB. Patients' attitudes and perceptions regarding social needs screening and navigation: multi-site survey in a large integrated health system. J Gen Intern Med 2020;35:1389-95.

86. Palakshappa D, Doupnik S, Vasan A, et al. Suburban families' experience with food insecurity screening in primary care practices. Pediatrics 2017;140:e20170320.

87. Hunter K, Thomson B. A scoping review of social determinants of health curricula in post-graduate medical education. Can Med Educ J 2019;10:e61e71.

88. Martinez J, Fornari A, VanHuse V, et al. A faculty development graduate medical education retreat to teach and address social determinants of health. J Med Educ Curric Dev 2020;7:238212052091549.

89. National Academies of Sciences, Engineering, and Medicine. A framework for educating health professionals to address the social determinants of health. Washington (DC): National Academies Press; 2016. 


\section{Appendix 1. Search Strategy}

Final search strategy table, January 9, 2018

\begin{tabular}{lccc}
\hline & All searches run on January 9, 2018. & Number of \\
\hline Date & Database & Search strategy & results
\end{tabular}

1/9/18 PubMed

("Social Determinants of Health" [Mesh] OR "social determinants" [tiab] OR

4326

"social determinant" [tiab] OR "determinants of health" [tiab] OR "determinant of health" [tiab] OR "social needs" [tiab] OR "unmet needs" [tiab] OR "nonmedi cal needs" [tiab] OR "psychosocial problems" [tiab] OR "food insecurity" [tiab] OR homeless [tiab] OR homelessness [tiab] OR "social hardship" [tiab] OR "social hardships" [tiab] OR "domestic violence" [tiab] OR "intimate partner violence" [tiab] OR transportation [tiab] OR "legal services" [tiab] OR "legal needs" [tiab] OR childcare [tiab] OR unemployment [tiab] OR poverty [tiab] OR literacy [tiab] OR GED [tiab] OR "english as a second language" [tiab] OR incarceration [tiab] OR reading [tiab] OR "child abuse" [majr] OR "child abuse" [tiab] OR "child maltreatment" [tiab] OR firearm [tiab] OR firearms [tiab] OR gun [tiab] OR guns [tiab] OR "youth violence" [tiab] OR "Social Isolation" [Mesh] OR "social isolation" [tiab] OR "food security" [tiab] OR employment [tiab] OR housing [tiab] OR housed [tiab])

AND

(physician [tiab] OR physicians [tiab] OR providers [tiab] OR provider [tiab] OR resident [tiab] OR residents [tiab] OR intern [tiab] OR interns [tiab] OR "medical student" [tiab] OR "medical students" [tiab] OR staff [tiab] OR clinician [tiab] OR clinicians [tiab] OR nurse [tiab] OR nurses [tiab] OR "medical assistant" [tiab] OR "medical assistants" [tiab] OR "medical director" [tiab] OR "medical directors" [tiab] OR "community health worker" [tiab] OR "community health workers" [tiab] OR "social worker" [tiab] OR "social workers" [tiab] OR "primary care" [tiab] OR "urgent care" [tiab] OR "emergency department" [tiab] OR navigator [tiab] OR navigators [tiab] OR advocate [tiab] OR advocates [tiab]) AND

("Mass Screening" [Majr] OR screening [tiab] OR screen [tiab] OR intervention [tiab] OR interventions [tiab] OR "needs assessment" [tiab] OR "need assessment" [tiab])

AND

(attitudes [tiab] OR attitude [tiab] OR perception [tiab] OR perceptions [tiab] OR belief [tiab] OR beliefs [tiab] OR knowledge [tiab] OR comfort [tiab] OR competence [tiab] OR behavior [tiab] OR acceptability [tiab] OR confidence [tiab] OR confident [tiab] OR opinion [tiab] OR opinions [tiab] OR burnout [tiab] OR satisfaction [tiab] OR "experience of care" [tiab] OR "provider patient relationship" [tiab] OR "experiences" [tiab])

1/9/18 Embase

(('social determinants of health'/exp OR "social determinants":ti,ab OR "social determinant":ti,ab OR "determinants of health":ti,ab OR "determinant of health":ti,ab OR "social needs":ti,ab OR "unmet needs":ti,ab OR "nonmedical nee ds":ti,ab OR "psychosocial problems":ti,ab OR "food insecurity":ti,ab OR homeless:ti,ab OR homelessness:ti,ab OR "social hardship":ti,ab OR "social hardships":ti,ab OR “domestic violence":ti,ab OR "intimate partner violence":ti, ab OR transportation: ti,ab OR "legal services":ti,ab OR “legal needs”:ti,ab OR childcare:ti,ab OR unemployment:ti,ab OR poverty:ti,ab OR literacy:ti,ab OR GED:ti,ab OR "english as a second language":ti,ab OR incarceration:ti,ab OR reading:ti,ab OR 'child abuse'/exp/mj O R "child abuse":ti,ab OR "child maltreatment":ti,ab OR firearm:ti,ab OR firearms:ti,ab OR gun:ti,ab OR guns:ti, ab OR "youth violence":ti,ab OR "social isolation":ti,ab OR "food security":ti,ab OR employment:ti,ab OR housing:ti,ab OR housed:ti,ab)

AND

(physician:ti,ab OR physicians:ti,ab OR providers:ti,ab OR provider:ti,ab OR resident:ti,ab OR residents:ti,ab OR intern:ti,ab OR interns:ti,ab OR "medical student":ti,ab OR “medical students":ti,ab OR staff:ti,ab OR clinician:ti,ab OR clinici ans:ti,ab OR nurse:ti,ab OR nurses:ti,ab OR "medical assistant”:ti,ab OR "medical assistants":ti,ab OR "medical director":ti,ab OR "medical directors":ti, ab OR "community health worker":ti,ab OR "community health workers":ti,ab 
All searches run on January 9, 2018.

$\begin{array}{llc}\text { Date } \quad \text { Database } & \text { Search strategy } & \text { Number of } \\ \text { results }\end{array}$

OR “social worker”:ti ,ab OR “social workers”:ti,ab OR “primary care”:ti,ab OR

"urgent care":ti,ab OR “emergency department”:ti,ab OR navigator:ti,ab OR navigators:ti,ab OR advocate:ti,ab OR advocates:ti,ab)

AND

('mass screening'/exp/mj OR screening:ti,ab OR screen:ti,ab OR intervention:ti, ab OR interventions:ti,ab OR "needs assessment":ti,ab OR "need assessment":ti, ab)

AND

(attitudes:ti,ab OR attitude:ti,ab OR perception:ti,ab OR perceptions:ti,ab OR belief:ti,ab OR beliefs:ti,ab OR knowledge:ti,ab OR comfort:ti,a b OR competence:ti,ab OR behavior:ti,ab OR acceptability:ti,ab OR confidence:ti,ab OR confident:ti,ab OR opinion:ti,ab OR opinions:ti,ab OR burnout:ti,ab OR satisfaction:ti,ab OR "experience of care":ti,ab OR "provider patient relationship":ti,ab OR experiences:ti,ab))

1/9/18 Web of Science

(("social determinants" OR "social determinant" OR "determinants of health" OR "determinant of health" OR "social needs" OR "unmet needs" OR "nonmedical needs" OR "psychosocial problems" OR "food insecurity" OR homeless OR homelessness OR "social hardship" OR "social hardships" OR "domestic violence" OR "intimate partner violence" OR transportation OR "legal services" OR "legal needs" OR childcare OR unemployment OR poverty OR literacy OR GED OR "english as a second 1 anguage" OR incarceration OR reading OR "child abuse" OR "child maltreatment" OR firearm OR firearms OR gun OR guns OR "youth violence" OR "social isolation" OR "food security" OR employment OR housing OR housed)

AND

(physician OR physicians OR providers OR provider OR re sident OR residents OR intern OR interns OR "medical student" OR "medical students" OR staff OR clinician OR clinicians OR nurse OR nurses OR "medical assistant" OR "medical assistants" OR "medical director" OR "medical directors" OR "community heal th worker" OR "community health workers" OR "social worker" OR "social workers" OR "primary care" OR "urgent care" OR "emergency department" OR navigator OR navigators OR advocate OR advocates)

AND

(screening OR screen OR intervention OR interventio ns OR "needs assessment" OR "need assessment")

AND

(health)

AND

(attitudes OR attitude OR perception OR perceptions OR belief OR beliefs OR knowledge OR comfort OR competence OR behavior OR acceptability OR confidence OR confident OR opinion OR opin ions OR burnout OR satisfaction OR "experience of care" OR "provider patient relationship" OR experiences))

1/9/18 PsycINFO

$\mathrm{ab}$ (("social determinants" OR "social determinant" OR "determinants of health" OR "determinant of health" OR "social needs" OR "unmet needs" OR "nonmedical needs" OR "psychosocial problems" OR "food insecurity" OR homeless OR home lessness OR "social hardship" OR "social hardships" OR "domestic violence" OR "intimate partner violence" OR transportation OR "legal services" OR "legal needs" OR childcare OR unemployment OR poverty OR literacy OR GED OR "english as a second language " OR incarceration OR reading OR "child abuse" OR "child maltreatment" OR firearm OR firearms OR gun OR guns OR "youth violence" OR "social isolation" OR "food security" OR employment OR housing OR housed))

AND

ab((physician OR physicians OR provide rs OR provider OR resident OR residents OR intern OR interns OR "medical student" OR "medical students" OR staff OR clinician OR clinicians OR nurse OR nurses OR "medical assistant" OR "medical assistants" OR "medical director" OR "medical directors " OR "community health worker" OR "community health workers" OR "social worker" OR "social workers" OR "primary care" OR "urgent care" OR "emergency department" OR navigator OR navigators OR advocate OR advocates)) 
All searches run on January 9, 2018.

\begin{tabular}{|c|c|c|c|}
\hline Date & Database & Search strategy & $\begin{array}{l}\text { Number of } \\
\text { results }\end{array}$ \\
\hline & & $\begin{array}{l}\text { AND } \\
\text { ab((screening OR screen OR int ervention OR interventions OR "needs } \\
\text { assessment" OR "need assessment")) } \\
\text { AND } \\
\text { ab((attitudes OR attitude OR perception OR perceptions OR belief OR beliefs } \\
\text { OR knowledge OR comfort OR competence OR behavior OR acceptability OR } \\
\text { confidence OR confident OR opinion OR opinions OR burnout OR satisfaction } \\
\text { OR "experience of care" OR "provider patient relationship" OR experiences)) }\end{array}$ & \\
\hline & TOTAL & & 19417 \\
\hline & Total duplicates & & 6123 \\
\hline & Total after de-duplication & & 13,294 \\
\hline
\end{tabular}

Continued 
Search update run on January 29, 2019.

\begin{tabular}{|c|c|c|c|}
\hline Date & Database & Search strategy & Number of results \\
\hline
\end{tabular}

AND

(physician:ti,ab OR physicians:ti,ab OR providers:ti,ab OR provider:ti,ab OR resident:ti,ab OR residents:ti,ab OR in tern:ti, ab OR interns:ti,ab OR "medical student":ti,ab OR "medical students":ti,ab OR staff:ti,ab OR clinician:ti,ab OR clinicians:ti, ab OR nurse:ti,ab OR nurses:ti,ab OR "medical assistant":ti,ab OR "medical assistants":ti,ab OR "medical director": ti,ab OR "medical directors":ti,ab OR "community health worker":ti,ab OR “community health workers":ti,ab OR "social worker":ti,ab OR “social workers”:ti,ab OR “primary care”:ti,ab OR "urgent care":ti,ab OR “emergency department":ti,ab OR navigator: ti, ab OR navigators:ti,ab OR advocate:ti,ab OR advocates:ti,ab) AND

('mass screening'/exp/mj OR screening:ti,ab OR screen:ti,ab OR intervention:ti,ab OR interventions:ti,ab OR "needs assessment":ti,ab OR "need assessment":ti,ab)

AND

(attitudes:ti,ab OR attitude:ti,ab OR perception:ti,ab OR perceptions:ti,ab OR belief:ti,ab OR beliefs:ti,ab OR knowledge: ti,ab OR comfort:ti,ab OR competence:ti,ab OR behavior:ti,ab OR acceptability:ti,ab OR confidence:ti,ab OR confident:ti,ab OR opinion:ti,ab OR opinions:ti,ab OR burnout:ti,ab OR satisfaction:ti,ab OR “experience of care":ti,ab OR "provider patient relationship”:ti,ab OR experiences:ti,ab)) AND [10-1-2018]/sd NOT [30-1-2019]/sd

"social determinants" OR "social determinant" OR

"determinants of health" OR "determinant of health" OR

"social needs" OR "unmet needs" OR "nonmedical needs" OR

"psychosocial problems" OR "food insecurity" OR homeless OR homelessness OR "social hardship" OR "social hardships"

OR "domestic viole nce" OR "intimate partner violence" OR transportation OR "legal services" OR "legal needs" OR childcare OR unemployment OR poverty OR literacy OR GED $O R$ "english as a second language" $O R$ incarceration OR reading OR "child abuse" OR "child maltreatme \? \nt" OR firearm OR firearms OR gun OR guns OR "youth violence" OR "social isolation" OR "food security" OR employment OR housing OR housed)

AND

(physician OR physicians OR providers OR provider OR resident OR residents OR intern OR interns OR "medica 1 student" OR "medical students" OR staff OR clinician OR clinicians OR nurse OR nurses OR "medical assistant" OR "medical assistants" OR "medical director" OR "medical directors" OR "community health worker" OR "community health workers" OR "social worker" OR "social workers" OR "primary care" OR "urgent care" OR "emergency department" OR navigator $O R$ navigators $O R$ advocate $O R$ advocates)

AND

(screening OR screen OR intervention OR interventions OR "needs assessment" OR "need assessment")

AND

(health)

AND

(attitudes OR attitude OR perception OR perceptions OR belief OR beliefs OR knowledge OR comfort OR competence OR behavior OR acceptability OR confidence OR confident OR opinion OR opinions OR burnout OR satisfaction OR "experience of care" OR "provider patient relationship" OR experiences))

IC Timespan = 2018-2019 
Updated search January 29, 2019

Continued

Search update run on January 29, 2019

\begin{tabular}{|c|c|c|c|}
\hline Date & Database & Search strategy & Number of results \\
\hline & & 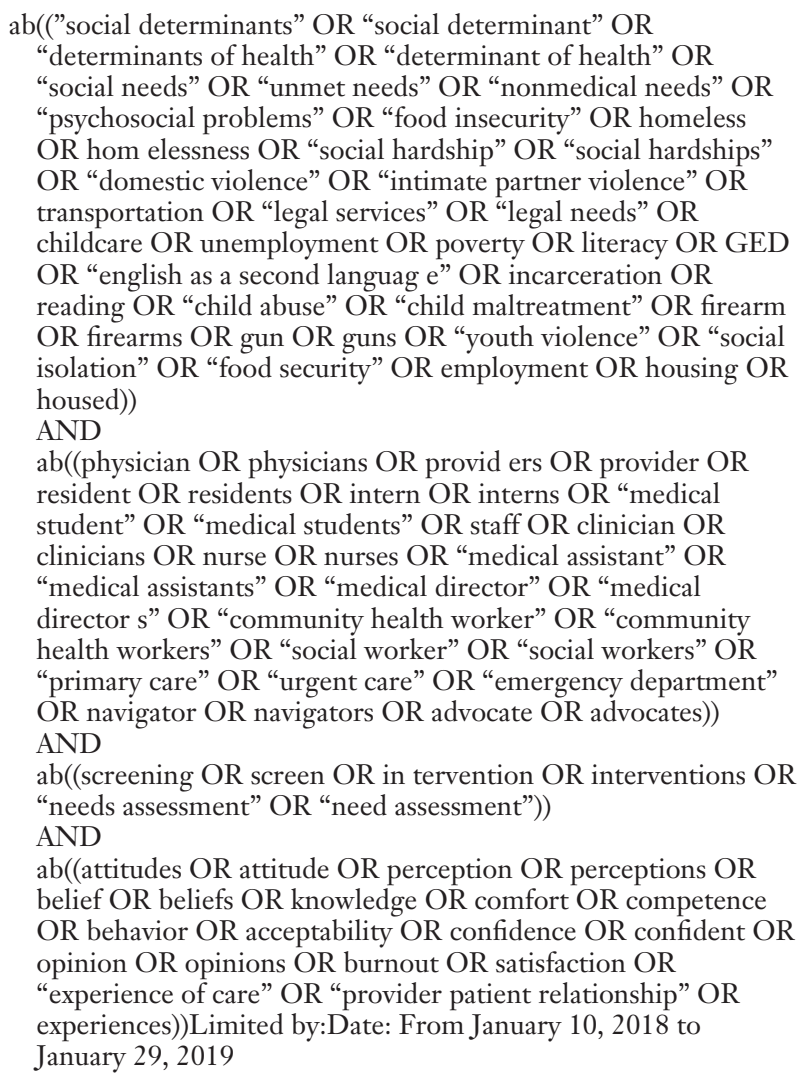 & \\
\hline Total & & & 2103 \\
\hline Number of duplicates & & & 655 \\
\hline Total after deduplication & & & 1448 \\
\hline
\end{tabular}




\begin{tabular}{|c|c|c|c|c|}
\hline Author, Year & $\begin{array}{l}\text { Target Social } \\
\text { Need(s) }\end{array}$ & Objective & $\begin{array}{l}\text { Provider Assessment Study } \\
\text { Design, Target Population and } \\
\text { Setting }\end{array}$ & Provider-Related Outcomes \\
\hline \multicolumn{5}{|c|}{ Screening Intervention Studies $(\mathrm{n}=23)$} \\
\hline $\begin{array}{l}\text { Knowles et al, } \\
2018^{34}\end{array}$ & Food insecurity & $\begin{array}{l}\text { Evaluate the efficacy of a clinic- } \\
\text { based integrated food } \\
\text { insecurity screening and } \\
\text { referral program implemented } \\
\text { in pediatric primary care. }\end{array}$ & $\begin{array}{l}\text { Study design: Qualitative process } \\
\text { evaluation using interviews \& } \\
\text { focus groups. } \\
\text { Sample: } 11 \text { clinic staff ( } 3 \\
\text { physicians, } 4 \text { administrative \& } \\
\text { clerical staff, } 3 \text { social workers, } \\
1 \text { research staff member) } \\
\text { Setting: } 3 \text { pediatric primary care } \\
\text { clinics }\end{array}$ & $\begin{array}{l}\text { Attitudes/Beliefs: Provider-identified } \\
\text { barriers to screening and referral } \\
\text { included complexity of } \\
\text { administration, concerns about } \\
\text { patient stigma and privacy, poor } \\
\text { referral communication, and } \\
\text { patients' enrollment in or lack of } \\
\text { eligibility for benefits. } \\
\text { Behavior: To reduce stigma, } \\
\text { physicians emphasized that } \\
\text { screening questions were asked of } \\
\text { all families. }\end{array}$ \\
\hline $\begin{array}{l}\text { Adams et al, } \\
2017^{58}\end{array}$ & Food insecurity & $\begin{array}{l}\text { Assess providers' attitudes during } \\
\text { the implementation of the } \\
\text { two-question food insecurity } \\
\text { (FI) screening tool and the } \\
\text { feasibility of providing } \\
\text { referrals and interventions. } \\
\text { Families complete paper } \\
\text { screen prior to visit. Providers } \\
\text { review form and provide } \\
\text { resource referrals accessible } \\
\text { through the EHR. }\end{array}$ & $\begin{array}{l}\text { Study design: Focus groups } \\
\text { Sample: Resident providers } \\
\text { Setting: Pediatric primary care } \\
\text { residency }\end{array}$ & $\begin{array}{l}\text { Attitudes/Beliefs: Providers reported } \\
\text { that FI screening was acceptable } \\
\text { and indicated that the screen/ } \\
\text { intervene model fit well into clinic } \\
\text { flow. Providers also noted that FI } \\
\text { screening opened discussions } \\
\text { around other SDoH. Providers } \\
\text { raised concerns about adding FI } \\
\text { status to problem lists and } \\
\text { suggested shorter resource lists. } \\
\text { Behavior: Providers documented FI } \\
\text { status in clinical notes but reported } \\
\text { difficulty remembering the relevant } \\
\text { International Classification of } \\
\text { Diseases code provided during } \\
\text { training. }\end{array}$ \\
\hline $\begin{array}{l}\text { O'Toole et al, } \\
2017^{52}\end{array}$ & Food insecurity & $\begin{array}{l}\text { Assess findings from a pilot } \\
\text { EHR-integrated food } \\
\text { insecurity screening and } \\
\text { referral program designed to } \\
\text { be administered by any } \\
\text { member of the health care } \\
\text { team. Positive screens referred } \\
\text { to care team members for } \\
\text { further assistance with social } \\
\text { or medical needs. }\end{array}$ & $\begin{array}{l}\text { Study design: Descriptive } \\
\text { evaluation including cross- } \\
\text { sectional surveys \& group } \\
\text { interviews } \\
\text { Sample: A survey of clinic } \\
\text { champions from each site ( } 3 \\
\text { nurse practitioners, } 2 \text { social } \\
\text { workers, } 1 \text { primary care } \\
\text { provider); group interviews } \\
\text { with representatives from all } 6 \\
\text { clinical sites; and } \\
\text { semistructured follow-up } \\
\text { interviews with each clinic's } \\
\text { care teams. } \\
\text { Setting: } 6 \text { Veterans } \\
\text { Administration HPACTs }\end{array}$ & $\begin{array}{l}\text { Attitudes/Beliefs: Care team members } \\
\text { universally endorsed the screening } \\
\text { and referral program. Staff } \\
\text { members reported favorable } \\
\text { feedback from patients and that } \\
\text { screening strengthened patient } \\
\text { connection with the health care } \\
\text { teams. Care teams believed } \\
\text { screening highlighted the need for } \\
\text { a multidisciplinary approach. No } \\
\text { team reported that screening was } \\
\text { burdensome. Teams identified } \\
\text { challenges with referrals. }\end{array}$ \\
\hline $\begin{array}{l}\text { Palakshapa et al, } \\
2017^{53}\end{array}$ & Food insecurity & $\begin{array}{l}\text { Evaluate the feasibility, } \\
\text { acceptability, and impact of an } \\
\text { EHR-integrated food } \\
\text { insecurity screening and } \\
\text { referral program in suburban } \\
\text { practices. Positive screens } \\
\text { were referred to a community } \\
\text { partner to assist with } \\
\text { enrollment in the } \\
\text { Supplemental Nutrition } \\
\text { Assistance Program. }\end{array}$ & $\begin{array}{l}\text { Study design: Prospective design } \\
\text { incorporating EHR data and } \\
\text { clinician focus groups } \\
\text { Sample: } 18 \text { pediatric primary } \\
\text { health care providers } \\
\text { Setting: } 6 \text { suburban pediatric } \\
\text { primary care clinics }\end{array}$ & $\begin{array}{l}\text { Attitudes/Beliefs: Themes from focus } \\
\text { groups suggest that clinicians do } \\
\text { not see time and workflow as } \\
\text { barriers to screening but do } \\
\text { identify lack of adequate resources } \\
\text { and concerns about embarrassing } \\
\text { families as barriers. Clinicians } \\
\text { report that parents felt screening } \\
\text { showed caring and were also } \\
\text { thankful to have been asked and to } \\
\text { receive resources. } \\
\text { Behavior: Some clinicians reported } \\
\text { that prefacing questions with } \\
\text { phrases to normalize screening (eg, }\end{array}$ \\
\hline
\end{tabular}

Continued 


\begin{tabular}{|c|c|c|}
\hline Author, Year & $\begin{array}{l}\text { Target Social } \\
\text { Need(s) }\end{array}$ & Objective \\
\hline $\begin{array}{l}\text { Gabrielian et al, } \\
2017^{49}\end{array}$ & Housing & $\begin{array}{l}\text { Assess feasibility and } \\
\text { acceptability of a pilot } \\
\text { initiative to collocate a } \\
\text { homeless-tailored patient- } \\
\text { centered medical home with } \\
\text { an emergency department } \\
\text { (ED), ED-HPACT. After } \\
\text { triage, low-acuity patients } \\
\text { appropriate for outpatient care } \\
\text { were screened for } \\
\text { homelessness; homeless } \\
\text { patients chose between the } \\
\text { collocated ED-HPACT or an } \\
\text { ED visit. }\end{array}$ \\
\hline
\end{tabular}

Provider Assessment Study

Design, Target Population and Setting
Study design: Observational analysis of postintervention provider surveys

Sample: 32 ED clinicians (physicians, nurses, social workers)

Setting: Veterans Affairs ED

Provider-Related Outcomes Chhabra et al,
$2019^{35}$
Explore clinical provider perspectives around a 2 -item homelessness screening clinical reminder (HSCR) integrated into the EHR across Veterans Health Affairs (VHA) outpatient clinics in 2012.
Study design: Qualitative indepth semistructured interviews

Sample: 22 providers were interviewed ( 20 physicians and two nurse practitioners)

Setting: VA Medical Center or associated community-based outpatient clinic
Pettignano et al, Legal services $2012^{50}$
Assess provider perceived impacts of a medical-legal partnership embedded in pediatric primary care. Providers refer families to the Health Law Partnership (HeLP) for legal needs.
Study design: Retrospective analysis of provider surveys Sample: Referring pediatric physicians, nurse case managers, social workers Setting: Pediatric primary care "these are questions we ask everyone") relieved discomfort. Screening rates ranged across practices and clinicians

Attitudes/Beliefs: Acceptability was mixed. Most providers (20, 66.7\%) strongly agreed or agreed that the intervention "is an effective way to improve the way that homeless Veterans use health services at the VA." Nearly all participants strongly agreed or agreed that "I would like to see the ED-HPACT program continue and be expanded." $42.0 \%$ of respondents strongly agreed or agreed with the statement: "Collocating HPACT within the ED works well"; $27.3 \%$ of nurses disagreed or strongly disagreed with: "Asking about homelessness during the triage process is the right time during the visit to ask patients about homelessness."

Knowledge: Providers reported that the HSCR broadened their understanding of housing instability.

Attitudes/Beliefs: Providers reported prioritizing medical over social care in brief clinical visits; highlighted both a sense of reward and futility in caring for vulnerable populations; and viewed the health system as having an important role to play in addressing housing concerns. Providers expressed concern over lack of resources to address housing instability. Opinions were mixed about whether providers should administer social risk screening.

Behavior: Increased provider assessment of housing status and shaped provider clinical decisionmaking. Providers reported that knowledge of patient housing instability influenced care plans (eg, ordering additional tests, elevating patients to higher levels of care, scheduling more frequent appointments).

Attitudes/Beliefs: $70 \%$ of providers who referred patients to HeLP reported that they believed the services provided by HeLP allowed them to reallocate time to other cases; $95 \%$ reported that working with HeLP resulted in a positive impact on their perceptions of working collaboratively with the legal community to serve patients. Compared to the previous fiscal 


\begin{tabular}{|c|c|c|c|}
\hline Author, Year & $\begin{array}{l}\text { Target Social } \\
\text { Need(s) }\end{array}$ & Objective & $\begin{array}{l}\text { Provider Assessment Study } \\
\text { Design, Target Population and } \\
\text { Setting }\end{array}$ \\
\hline $\begin{array}{l}\text { Cohen et al, } \\
2010^{55}\end{array}$ & Legal needs & $\begin{array}{l}\text { Describe exemplar medical-legal } \\
\text { partnership (MLP) training } \\
\text { programs for residents, } \\
\text { students, and other health care } \\
\text { providers on how social } \\
\text { conditions impact health, } \\
\text { screening for unmet social } \\
\text { needs, and the impact of } \\
\text { enforcing federal and state } \\
\text { laws. }\end{array}$ & $\begin{array}{l}\text { Study design: Presurvey/ } \\
\text { postsurvey \& qualitative } \\
\text { assessment } \\
\text { Sample: } 4 \text { MLP training } \\
\text { programs; pediatric and } \\
\text { internal medicine residents, } \\
\text { medical students, and allied } \\
\text { health professionals } \\
\text { Setting: Four MLP training } \\
\text { programs }\end{array}$ \\
\hline
\end{tabular}

$\begin{gathered}\text { Sand-Jecklin et Health literacy } \\ \text { al, } 2017^{48}\end{gathered}$
$\begin{gathered}\text { Determine the feasibility of } \\ \text { incorporating the Expanded } \\ \text { Brief Health Literacy Screen } \\ \text { (EBHLS) questions into the } \\ \text { EHR of a large teaching } \\ \text { hospital. A "flag" added to the } \\ \text { admission database triggered } \\ \text { nurses to complete the health } \\ \text { literacy (HL) assessment for } \\ \text { adult patients upon admission. }\end{gathered}$

Seligman et al, Health literacy Determine if notifying physicians $2005^{25}$

Study design: RCT of their patients' limited health literacy (HL) affects physician behavior, physician satisfaction, or patient selfefficacy. Providers were randomized to be notified if their diabetes patients had limited HL skills.
Study design: Descriptive analysis of postintervention surveys

Sample: 115 nurses

Setting: Large urban teaching hospital

Sample: 63 attending and resident primary care physicians (31 received notification of patients' limited health literacy; 32 did not)

Setting: Primary care
Provider-Related Outcomes

year, $33.5 \%$ more providers indicated that they believed that HeLP services helped to decrease emergency department visits, $22.4 \%$ more believed that HeLP services helped to decrease readmissions, and $32.4 \%$ more felt that HeLP services helped to decrease inpatient length of stay.

Knowledge: MLP training programs increased resident knowledge of patient resources and helped residents understand poverty.

Attitudes/Beliefs: MLP training programs reduced concern about making patients nervous with legal questions and improved resident capacity to screen for 2 unmet basic needs.

Behavior: MLP programs increased screening for social needs, referrals to legal services, and assistance with obtaining government benefits.

Attitudes /Beliefs: Overall, nurses found HL screening acceptable and helpful for patient care. Narrative comments indicated that some RNs felt the questions were repetitive $(n=8)$, felt that at times patients did not understand the questions $(n=7)$ or were annoyed by them $(n=6)$, and felt that patients may not answer the questions honestly $(n=4)$.

Behavior: Over a 4-month period, nurses completed HL assessment for 25,557 of 31,195 (82\%) of all admitted adult patients.

Knowledge: Physicians in the intervention group overestimated the HL level of $62 \%$ of their patients.

Attitudes/Beliefs: Physicians in the intervention group felt screening for HL was useful in $64 \%$ of visits and that increased access to allied health professionals (88\%) and case management services (64\%) would be useful. They also reported feeling less satisfied with their visits than physicians in the control group.

Behavior: Notified physicians were more likely than physicians in the control group to use recommended management strategies for patients with limited HL (OR 3.2, P =.04). Intervention group physicians engaged in discussions about HL 


\begin{tabular}{|c|c|c|}
\hline Author, Year & $\begin{array}{l}\text { Target Social } \\
\text { Need(s) }\end{array}$ & Objective \\
\hline $\begin{array}{l}\text { Wahab et al, } \\
2018^{41}\end{array}$ & Health literacy & $\begin{array}{l}\text { Improve internal medicine } \\
\text { resident physicians' health } \\
\text { literacy (HL) knowledge and } \\
\text { ability to predict patients with } \\
\text { low HL and improve patient } \\
\text { care. An HL education } \\
\text { intervention paired with } \\
\text { patient screening for HL. }\end{array}$ \\
\hline $\begin{array}{c}\text { Byhoff et al, } \\
2019^{60}\end{array}$ & $\begin{array}{l}\text { Multiple social } \\
\text { needs }\end{array}$ & $\begin{array}{l}\text { Understand the facilitators and } \\
\text { barriers to implementing the } \\
\text { WE CARE SDoH screening } \\
\text { and referral tool in CHCs } \\
\text { during well-child visits. }\end{array}$ \\
\hline
\end{tabular}

Provider Assessment Study

Design, Target Population and

Setting

Provider-Related Outcomes

Study design: Pre-education/ posteducation quality improvement project

Sample: 10 residentsSetting: Inpatient care

screening results with $2 \%$ of patients and planned future discussions in $27 \%$.

Knowledge: Resident pre-HL and post-HL knowledge did not change. Eismann et al,
$2018^{56}$ $\begin{gathered}\text { Multiple social } \\ \text { needs }\end{gathered}$ implementing the Safe Environment for Every Kid (SEEK) model for addressing psychosocial risk factors for maltreatment.

Providers used the SEEK screening tool to identify and address psychosocial problems associated with child maltreatment through motivational interviewing and referrals.
Study design: Qualitative implementation evaluation of provider/staff focus groups Sample: 9 physicians, 3 nurses, and 14 medical assistants.

Setting: 3 CHC primary care clinics

Study design: Observational analysis of provider interviews, surveys, and chart review

Attitudes/Beliefs: Provider and staff experiences with the $\mathrm{SDOH}$ screening/referral program and perceptions of faciliators and barriers to sustainable program implementation were mixed. Some respondents raised concerns about negative patient reactions to the screening tool, additional time needed to screen, and referral workflow confusion. Others believed the tool facilitated important provider-patient conversations and did not add time to visits. Participants agreed that the addition of a patient navigator was positive. Additional perceived faciliators included previous experience with psychosocial screening, site resources to address identified needs, and EHRintegrated referral resources guides. Differences in barriers and faciliators were noted between clinical sites rather than providers and staff.

Knowledge: Providers reported learning about local resources and improved conversational skills related to psychosocial concerns.

ample: 20 primary care physicians Setting: 3 primary care practices Attitudes/Beliefs: Providers felt better able to meet their families' needs and to provide whole-person care because they had a better understanding of their families' social situations. Providers generally endorsed the SEEK model as part of standard clinical care. Provider-identified implementation barriers included limited time during well-child visits, incomplete knowledge of resources, insufficient resources, and offending caregivers. Providers reported that on-site support staff to connect families with resources was the most important program facilitator. Time burden was less than anticipated preimplementation

Behavior: Physicians increased practices that addressed 


\begin{tabular}{|c|c|c|c|}
\hline Author, Year & $\begin{array}{l}\text { Target Social } \\
\text { Need(s) }\end{array}$ & Objective & $\begin{array}{l}\text { Provider Assessment Study } \\
\text { Design, Target Population an } \\
\text { Setting }\end{array}$ \\
\hline
\end{tabular}

Hamity et al, $2018^{59}$
Assess the impact of incorporating social needs assessments into clinical care on clinicians, staff, \& patients.
Study design: Descriptive analysis of qualitative interviews, focus groups, \& surveys

Sample: 90 clinicians \& staff Setting: Large health system $\begin{array}{cc}\text { Patel et al, } & \begin{array}{c}\text { Multiple social } \\ \text { needs }\end{array}\end{array}$

Sundar, $2018^{33}$
Multiple needs

Multiple social
needs

Assess the impact of SDoH residency training module and visual reminder intervention to use a formal social historytaking tool (IHELLP) in pediatric primary patient care.

Address key stakeholder concerns about implementing universal screening for social needs using Your Current Life Situation tool through a frontline quality improvement project.

\section{Tong et al $2018^{54}$}

Understand provider experiences administering a social needs screening tool. Providers reviewed completed social needs surveys with patients during clinical encounters and completed a structured diary for each patient following the visit. Concurrently, providers participated in a learning collaborative series focused on
Study design: Pre-education/ posteducation intervention chart review of well-child visits

Sample: $\mathrm{n}=92-130$ (variable sample sizes at each phase of study); pediatric residents

Setting: Pediatric primary care residency

Study design: Quality improvement evaluation including informal conversations and group discussions

Sample: 6 primary care staff (1 family medicine physician, 1 clinic manager, 1 researcher, 1 behavioral health services manager, and 2 community resource specialists)

Setting: Primary care

Study design: Prospective observational design including social needs learning collaborative and structured diaries

Sample: 17 primary care providers

Setting: 12 primary care practices in one health system
Provider-Related Outcomes

psychosocial concerns. Most physicians were not routinely addressing these psychosocial concerns prior to implementation.

Knowledge: Surveyed clinicians reported an awareness of patients' priority social needs and available resources.

Attitudes/Beliefs: Clinicians believed social needs impact health outcomes and that equipping care teams with patients' social information could improve care and build trust. In discussion groups, staff and clinicians reported that assessing social needs was an opportunity to obtain valuable information to inform care decisions and improve communication with their patients. Clinicians highlighted concerns about having too much information and recommended simple screening formats, such as yes/no questions. Reasons for not assessing social needs included lack of time and available resources.

Behavior: Clinicians reported using patients' social needs information in medical decisions and care planning.

Behavior: Increased resident documentation of family income and housing. Residents were also more likely to discuss and document Special Supplemental Nutrition Program for Women, Infants, and Children and Supplemental Nutrition Assistance Program benefits.

Attitudes/Beliefs: Clinicians and MAs reported no disruption to clinic workflow and enthusiasm around social screening implementation. Patients' engagement in screening reduced medical teams' concerns.

Attitudes/Beliefs: In 52\% of encounters, clinicians reported that the social needs survey helped them to know and better understand their patients. Clinicians identified value in improving interactions with patients through assessing social needs. Clinicians expressed concern about the difficulty of screening, being overwhelmed with 


\begin{tabular}{|c|c|c|c|c|}
\hline Author, Year & $\begin{array}{l}\text { Target Social } \\
\text { Need(s) }\end{array}$ & Objective & $\begin{array}{l}\text { Provider Assessment Study } \\
\text { Design, Target Population and } \\
\text { Setting }\end{array}$ & Provider-Related Outcomes \\
\hline & & $\begin{array}{l}\text { how to address social needs in } \\
\text { patient care and completed } \\
\text { diary entries after seeing } \\
\text { patients about how knowledge } \\
\text { of a patient's social needs } \\
\text { influenced their care. }\end{array}$ & & $\begin{array}{l}\text { too much information and } \\
\text { administrative burden, insufficient } \\
\text { resources to help patients with } \\
\text { identified needs, and whether the } \\
\text { health system was the right place to } \\
\text { address social needs. } \\
\text { Behavior: For } 23 \% \text { of patients, } \\
\text { clinicians reported changing care } \\
\text { delivery in response to learning of } \\
\text { patients' social needs. }\end{array}$ \\
\hline $\begin{array}{l}\text { Zielinski et al, } \\
2017^{39}\end{array}$ & $\begin{array}{l}\text { Multiple social } \\
\text { needs }\end{array}$ & $\begin{array}{l}\text { Evaluate the implementation of } \\
\text { the Well-Child Care Visit, } \\
\text { Evaluation, Community } \\
\text { Resources, Advocacy, } \\
\text { Referral, Education (ie, WE } \\
\text { CARE) at well-child visits and } \\
\text { the impact of identifying } \\
\text { psychosocial risk factors } \\
\text { associated with child neglect. } \\
\text { Positive screens were referred } \\
\text { to social workers for } \\
\text { assistance. }\end{array}$ & $\begin{array}{l}\text { Study design: Presurvey/ } \\
\text { postsurvey } \\
\text { Sample: } 46 \text { ( } 27 \text { pre; } 19 \text { post) } \\
\text { pediatricians, residents, and } \\
\text { nurse practioners } \\
\text { Setting: Pediatric primary care }\end{array}$ & $\begin{array}{l}\text { Attitudes/Beliefs: Provider comfort } \\
\text { with screening for social risks } \\
\text { increased over time. Most } \\
\text { providers believed the WE CARE } \\
\text { screen was likely to disrupt flow } \\
\text { before the intervention, but a } \\
\text { strong majority reported minimal } \\
\text { disruption after the intervention. } \\
\text { Behavior: Time to complete screen } \\
\text { decreased over time. } 602 \text { ( } 75 \% \text { ) of } \\
\text { the WE CARE forms were } \\
\text { completed among those eligible. }\end{array}$ \\
\hline $\begin{array}{l}\text { Colvin et al, } \\
2016^{29}\end{array}$ & $\begin{array}{l}\text { Multiple social } \\
\text { needs }\end{array}$ & $\begin{array}{l}\text { Determine whether a brief } \\
\text { training on the IHELP social } \\
\text { needs screening tool could } \\
\text { improve resident social needs } \\
\text { screening activities. Residents } \\
\text { were trained on the } \\
\text { relationship between social } \\
\text { needs and child health } \\
\text { followed by training on the } \\
\text { IHELP expanded social } \\
\text { history tool for use during } \\
\text { inpatient admission. }\end{array}$ & $\begin{array}{l}\text { Study design: Nonrandomized } \\
\text { comparison study } \\
\text { Sample: } 106 \text { pediatric residents } \\
\text { Setting: Inpatient pediatric } \\
\text { residency }\end{array}$ & $\begin{array}{l}\text { Behavior: More than } 80 \% \text { of residents } \\
\text { from the intervention team } \\
\text { documented use of IHELP } \\
\text { compared with } 16.5 \% \text { of the } \\
\text { comparison group; the intervention } \\
\text { team's percentage of social work } \\
\text { consults was nearly } 3 \text { times greater } \\
\text { than on the comparison team's }(P< \\
.001) \text {. }\end{array}$ \\
\hline $\begin{array}{l}\text { Page-Reeves et } \\
\text { al, } 2016^{51}\end{array}$ & Multiple needs & $\begin{array}{l}\text { Assess the feasibility of } \\
\text { implementing a social needs } \\
\text { screening tool in a general } \\
\text { primary care clinic setting. } \\
\text { Patients who screened positive } \\
\text { were offered assistance in } \\
\text { connecting with services and } \\
\text { resources by MAs or CHWs. }\end{array}$ & $\begin{array}{l}\text { Study design: Feasibility study } \\
\text { including provider observation } \\
\text { and journal entries } \\
\text { Sample: } 6 \text { providers } \\
\text { Setting: } 3 \text { family medicine clinics }\end{array}$ & $\begin{array}{l}\text { Attitudes/Beliefs: Providers believed } \\
\text { that expanding the MA role to } \\
\text { identify patient social issues and } \\
\text { the CHW intervention lightened } \\
\text { their workloads and increased } \\
\text { confidence in the quality of patient } \\
\text { care. } \\
\text { Behavior: Enhanced the MA role. }\end{array}$ \\
\hline $\begin{array}{l}\text { Feigelman et al, } \\
2011^{27}\end{array}$ & $\begin{array}{l}\text { Multiple social } \\
\text { needs }\end{array}$ & $\begin{array}{l}\text { Determine the impact of resident } \\
\text { training on the Safe } \\
\text { Environment for Every Kid } \\
\text { (SEEK) model. Pediatric } \\
\text { residents receive training } \\
\text { about psychosocial risk factors } \\
\text { and a screening tool to } \\
\text { identify and address } \\
\text { psychosocial problems } \\
\text { associated with child } \\
\text { maltreatment. }\end{array}$ & $\begin{array}{l}\text { Study design: RCT } \\
\text { Sample: } 95 \text { residents ( } 45 \text { SEEK, } \\
\quad 45 \text { usual care) } \\
\text { Setting: Pediatric primary care } \\
\quad \text { residency }\end{array}$ & $\begin{array}{l}\text { Knowledge: Residents participating in } \\
\text { SEEK improved their knowledge } \\
\text { in assessing } 4 \text { out of } 6 \text { risk areas } \\
\text { more than those in the control } \\
\text { group. } \\
\text { Behavior: Residents participating in } \\
\text { SEEK were more likely to screen } \\
\text { for targeted risk factors than } \\
\text { controls. }\end{array}$ \\
\hline $\begin{array}{l}\text { Garg, et al, } \\
2007^{26}\end{array}$ & $\begin{array}{l}\text { Multiple social } \\
\text { needs }\end{array}$ & $\begin{array}{l}\text { Evaluate the feasibility and } \\
\text { impact of screening and } \\
\text { intervening on family } \\
\text { psychosocial topics at well- } \\
\text { child care visits. Parents } \\
\text { completed the WE CARE } \\
\text { psychosocial screening tool }\end{array}$ & $\begin{array}{l}\text { Study design: RCT } \\
\text { Sample: } 45 \text { residents ( } 24 \\
\text { intervention, } 21 \text { control) } \\
\text { Setting: Urban hospital-based } \\
\text { pediatric primary care clinic }\end{array}$ & $\begin{array}{l}\text { Attitudes/Beliefs: Residents reported } \\
\text { no discomfort with receiving WE } \\
\text { CARE survey from parents. The } \\
\text { majority of residents in the } \\
\text { intervention group reported that } \\
\text { the survey instrument did not slow } \\
\text { the visit. }\end{array}$ \\
\hline
\end{tabular}




\begin{tabular}{|c|c|c|c|c|}
\hline Author, Year & $\begin{array}{l}\text { Target Social } \\
\text { Need(s) }\end{array}$ & Objective & $\begin{array}{l}\text { Provider Assessment Study } \\
\text { Design, Target Population and } \\
\text { Setting }\end{array}$ & Provider-Related Outcomes \\
\hline & & $\begin{array}{l}\text { before well-child care visits } \\
\text { and received referrals from } \\
\text { resident physicians during } \\
\text { visits. }\end{array}$ & & $\begin{array}{l}\text { Behavior: Increased parent-provider } \\
\text { discussion of psychosocial topics } \\
\text { and referrals for social needs. }\end{array}$ \\
\hline $\begin{array}{l}\text { Dorr et al, } \\
2007^{28}\end{array}$ & Multiple needs & $\begin{array}{l}\text { Assess the impact of a care } \\
\text { management system on } \\
\text { primary care physician } \\
\text { efficiency and productivity. }\end{array}$ & $\begin{array}{l}\text { Study design: Retrospective } \\
\text { controlled repeated-measures } \\
\text { comparison } \\
\text { Sample: } 120 \text { physicians in } 7 \\
\text { intervention and } 14 \text { control } \\
\text { primary care clinics } \\
\text { Setting: } 21 \text { primary care clinics }\end{array}$ & $\begin{array}{l}\text { Behavior: Physician productivity } \\
\text { significantly increased when more } \\
\text { than } 2 \% \text { of patients were seen by } \\
\text { care management team. }\end{array}$ \\
\hline \multicolumn{5}{|c|}{ Provider Education Intervention Studies $(\mathrm{n}=13)$} \\
\hline $\begin{array}{l}\text { Kangovi et al, } \\
2018^{37}\end{array}$ & $\begin{array}{l}\text { Multiple social } \\
\text { needs }\end{array}$ & $\begin{array}{l}\text { Describe a critical service- } \\
\text { learning rotation in which } \\
\text { medical students serve as } \\
\text { apprentices to CHWs. } \\
\text { Learning objectives of this } \\
\text { rotation are (1) to understand } \\
\text { challenges low-income } \\
\text { patients faced in maintaining } \\
\text { health; (2) to develop cross- } \\
\text { cultural communication and } \\
\text { negotiation skills; (3) to learn } \\
\text { health care resources available } \\
\text { to low-income patients; (4) to } \\
\text { advocate in the health care } \\
\text { setting for patients to obtain } \\
\text { needed care and services. }\end{array}$ & $\begin{array}{l}\text { Study design: Qualitative analysis } \\
\text { of interviews } \\
\text { Sample: } 16 \text { medical students, } 4 \\
\text { CHWs } \\
\text { Setting: Medical school }\end{array}$ & $\begin{array}{l}\text { Attitudes/Beliefs: Students reported } \\
\text { feeling more optimistic and began } \\
\text { to view difficult psychosocial } \\
\text { barriers as modifiable. The } \\
\text { rotation enhanced students' } \\
\text { cultural humility and confidence in } \\
\text { addressing SDoH. }\end{array}$ \\
\hline $\begin{array}{l}\text { Onyekere et al, } \\
2016^{36}\end{array}$ & $\begin{array}{l}\text { Multiple social } \\
\text { needs }\end{array}$ & $\begin{array}{l}\text { Describe the impact of the } \\
\text { Medical Student Advocate } \\
\text { (MSA) program, which places } \\
\text { volunteer osteopathic medical } \\
\text { students in care coordination } \\
\text { teams to address patients' } \\
\text { nonmedical resource needs } \\
\text { such as food, employment, } \\
\text { childcare, and transportation. }\end{array}$ & $\begin{array}{l}\text { Study design: Descriptive } \\
\text { analysis of program data } \\
\text { collected between August } \\
2013 \text { and August } 2015 ; \\
\text { qualitative analysis of student } \\
\text { reflection sessions } \\
\text { Sample: } 31 \text { medical students } \\
\text { Setting: Primary care clinic }\end{array}$ & $\begin{array}{l}\text { Knowledge: Increased understanding } \\
\text { of SDoH and the impact on } \\
\text { patients. } \\
\text { Attitudes/Beliefs: Increased empathy } \\
\text { toward patients and confidence } \\
\text { entering third-year clerkships. }\end{array}$ \\
\hline $\begin{array}{l}\text { Real et al, } \\
2016^{46}\end{array}$ & $\begin{array}{l}\text { Multiple social } \\
\text { needs }\end{array}$ & $\begin{array}{l}\text { Assess impact of neighborhood- } \\
\text { based curriculum designed to } \\
\text { improve residents' familiarity } \\
\text { with local neighborhoods and } \\
\text { resources. Residents } \\
\text { participated in } 3 \text { 30-minute } \\
\text { small-group teaching modules } \\
\text { focused on a specific subset of } \\
\text { SDoH-related issues within } \\
\text { local neighborhoods. }\end{array}$ & $\begin{array}{l}\text { Study design: Presurvey/ } \\
\text { postsurvey } \\
\text { Sample: } 37 \text { pediatric residents } \\
\text { Setting: Pediatric residency } \\
\text { program }\end{array}$ & $\begin{array}{l}\text { Knowledge: Completing curriculum } \\
\text { led more residents to assess } \\
\text { themselves as competent or better } \\
\text { for locating safe places for children } \\
\text { (from } 43.2 \text { to } 75.7 \% ; P<0.05) \text {; and } \\
\text { highly experienced or expert in the } \\
\text { ability to advise families on safe } \\
\text { play (from } 10.8 \text { to } 32.4 \% \text {; } \\
P<0.05 \text { ). Self-assessed competence } \\
\text { for assisting families with } \\
\text { transportation also significantly } \\
\text { increased (from } 59.5 \text { to } 83.8 \% ; \\
P<0.05) \text {. } \\
\text { Behavior: In the postcurriculum } \\
\text { period, } 49 \% \text { of residents reported } \\
\text { always or frequently asking families } \\
\text { about their neighborhood } \\
\text { compared to } 19 \% \text { prior }(P<0.01) ; \\
\text { and } 97 \% \text { reported being able to } \\
\text { identify a relevant neighborhood } \\
\text { resources website compared with } \\
25 \% \text { prior }(P<0.0001) .\end{array}$ \\
\hline
\end{tabular}




\begin{tabular}{|c|c|c|c|c|}
\hline Author, Year & $\begin{array}{l}\text { Target Social } \\
\text { Need(s) }\end{array}$ & Objective & $\begin{array}{l}\text { Provider Assessment Study } \\
\text { Design, Target Population and } \\
\text { Setting }\end{array}$ & Provider-Related Outcomes \\
\hline $\begin{array}{l}\text { Girotti et al, } \\
2015^{31}\end{array}$ & $\begin{array}{l}\text { Multiple social } \\
\text { needs }\end{array}$ & $\begin{array}{l}\text { Assess the effectiveness of an } \\
\text { urban medicine program, } \\
\text { UMed, designed to prepare } \\
\text { students for the roles of } \\
\text { advocate, researcher, policy } \\
\text { maker, and culturally } \\
\text { competent practitioner } \\
\text { through a 4-year curriculum } \\
\text { integrating principles of } \\
\text { public health with direct } \\
\text { interventions in local, } \\
\text { underserved communities. }\end{array}$ & $\begin{array}{l}\text { Study design: Pre-evaluation/ } \\
\text { postevaluation of seminar } \\
\text { assessments and } \\
\text { nonrandomized group } \\
\text { comparisons } \\
\text { Sample: } 99 \text { medical students } \\
\text { Setting: Medical school }\end{array}$ & $\begin{array}{l}\text { Attitudes/Beliefs: Trainees in the } \\
\text { program were more likely than } \\
\text { nonparticipants to endorse that } \\
\text { "Universal medical care is a right" } \\
{[P=.01], \text { "Access to basic medical }} \\
\text { care is a right" }[P=.03] \text {, "Access is } \\
\text { influenced by social determinants" } \\
[P=.03]) .\end{array}$ \\
\hline $\begin{array}{l}\text { O'Brien et al, } \\
2014^{38}\end{array}$ & $\begin{array}{l}\text { Multiple social } \\
\text { needs }\end{array}$ & $\begin{array}{l}\text { Assess the impact of a 9-month } \\
\text { pilot service-learning course } \\
\text { on the social determinants of } \\
\text { health combining didactic } \\
\text { instruction with service } \\
\text { experience in a community } \\
\text { health center. }\end{array}$ & $\begin{array}{l}\text { Study design: Surveys \& written } \\
\text { reflections } \\
\text { Sample: } 12 \text { medical and other } \\
\text { health professional students } \\
\text { Setting: Primary care }\end{array}$ & $\begin{array}{l}\text { Knowledge: Participants reported } \\
\text { learning more about the health } \\
\text { challenges facing vulnerable } \\
\text { populations through this program } \\
\text { than through curricular efforts in } \\
\text { their medical schools }\end{array}$ \\
\hline $\begin{array}{l}\text { Klein, et al, } \\
2014^{43}\end{array}$ & $\begin{array}{l}\text { Multiple social } \\
\text { needs }\end{array}$ & $\begin{array}{l}\text { Evaluate the impact of a } \\
\text { facilitated video SDoH } \\
\text { screening training. } \\
\text { Curriculum included } \\
\text { videotaped vignettes of } \\
\text { screening for SDoH and a } \\
\text { "day in the life" series of } \\
\text { families describing the impact } \\
\text { of intervention on their lives. }\end{array}$ & $\begin{array}{l}\text { Study design: Presurveys/ } \\
\text { postsurveys with concurrent } \\
\text { control } \\
\text { Sample: } 47 \text { pediatric residents } \\
\quad \text { ( } 24 \text { intervention, } 23 \text { control) } \\
\text { Setting: Pediatric primary care } \\
\text { residency }\end{array}$ & $\begin{array}{l}\text { Knowledge: After education, the } \\
\text { intervention group's self-rated } \\
\text { competence in screening for } \\
\text { housing, benefits, and educational } \\
\text { concerns and their ability to } \\
\text { provide resources was significantly } \\
\text { better than the control group's. } \\
\text { Attitudes/Beliefs: Both groups } \\
\text { identified time as the greatest } \\
\text { barrier ( }>85 \%) \text { to screening on } \\
\text { both the preintervention and } \\
\text { postintervention surveys. } \\
\text { Compared to controls, residents in } \\
\text { the intervention group reported } \\
\text { decreases in concerns about lack of } \\
\text { solutions ( } 46 \% \text { to } 38 \%) \text { and } \\
\text { discomfort with screening ( } 92 \% \text { to } \\
79 \%) . \text { None of the residents } \\
\text { identified SDoH screening as an } \\
\text { inappropriate activity for } \\
\text { physicians. } \\
\text { Behavior: Screening for each SDoH } \\
\text { was higher in the intervention } \\
\text { group with domestic violence }(\mathrm{OR} \\
2.16,95 \% \text { confidence interval } \\
1.01-4.63) \text { and depression }(\mathrm{OR} \\
2.63,95 \% \text { confidence interval } \\
1.15-5.99) . \text { MLP referral rates } \\
\text { increased ( } P=.06) \text { and formula } \\
\text { distribution ( } P=.02) \text { reached } \\
\text { statistical significance in the } \\
\text { intervention group. }\end{array}$ \\
\hline $\begin{array}{l}\text { Klein et al, } \\
2011^{44}\end{array}$ & $\begin{array}{l}\text { Multiple social } \\
\text { needs }\end{array}$ & $\begin{array}{l}\text { Examine the effects of an SDoH } \\
\text { health curriculum on pediatric } \\
\text { interns' attitudes, knowledge, } \\
\text { documentation, \& clinical } \\
\text { practice. Interns participated } \\
\text { in 1-year SDoH curriculum } \\
\text { including shadowing social } \\
\text { workers, interactive didactic } \\
\text { program, SDoH-focused } \\
\text { lectures, and access to legal } \\
\text { consultation. }\end{array}$ & $\begin{array}{l}\text { Study design: Nonrandomized } \\
\text { study of educational } \\
\text { intervention including } \\
\text { presurveys/postsurveys and } \\
\text { medical record review } \\
\text { Sample: } 38 \text { pediatric residents } \\
\text { (20 intervention, } 18 \text { control) } \\
\text { Setting: Pediatric residency } \\
\text { program }\end{array}$ & $\begin{array}{l}\text { Knowledge: Resident knowledge was } \\
\text { greater in the intervention group } \\
\text { post-test in all domains: benefits } \\
\text { ( } 72 \% \text { vs } 52 \% \text { ), housing ( } 48 \% \text { vs } \\
21 \% \text { ), and education ( } 52 \% \text { vs } 33 \% \text {; } \\
P<.001 \text { for all). } \\
\text { Attitudes/Beliefs: No differences } \\
\text { observed between groups regarding } \\
\text { the importance of social hardships } \\
\text { or screening for food security or } \\
\text { education issues. }\end{array}$ \\
\hline
\end{tabular}

Continued 


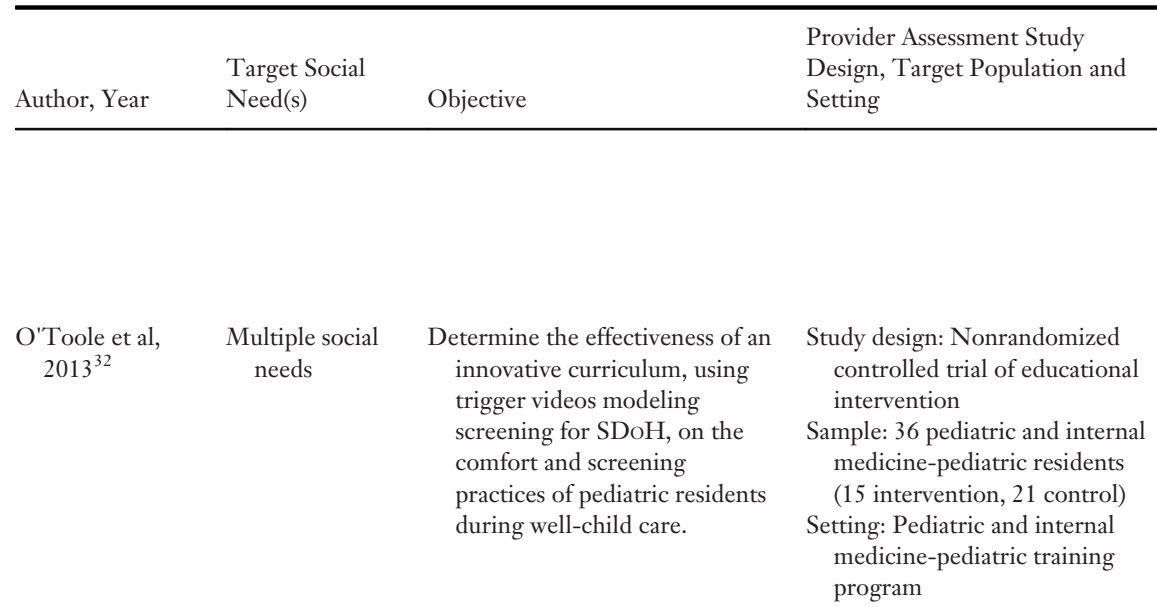

Kuo et al, 2011 $30 \quad$ Multiple social Evaluate the impact of needs Community Health and Advocacy Training (CHAT), a public health approach to pediatric residency education on learner knowledge, skills, attitudes, beliefs, and career choice.
Provider-Related Outcomes

Behavior: Interns in the intervention group were more likely to document each social risk (benefits $98 \%$ vs $60 \%$, housing $93 \%$ vs $57 \%$, food $74 \%$ vs $56 \% ; P<.001$ for all).

Knowledge: Following the intervention, there were no statistically significant differences between the control and intervention groups with respect to self-reported knowledge of and screening practices for various SDoH (housing, public benefits, domestic violence, food security, and maternal depression).

Attitudes/Beliefs: Intervention residents perceived fewer barriers to screening and were less likely to note barriers related to lack of knowledge, time, and comfort.

Behavior: Intervention residents were observed to spend more time on social risk screening than controls $(P=0.46)$ and inquired more frequently about family supports and housing conditions $(P=0.45)$.

Study design: Quasiexperimental pre-evaluation/ postevaluation Sample: 252 (215 categorical; 37 CHAT program) pediatric residents

Setting: Pediatric residency programs

Knowledge Residents in both training programs reported statistically significant gains in both selfperceived skill and community pediatrics resource knowledge scores during residency.

Attitudes/Beliefs: Residents who participated in the CHAT

\begin{tabular}{|c|c|c|c|}
\hline $\begin{array}{l}\text { Smith et al, } \\
2017^{45}\end{array}$ & Food insecurity & $\begin{array}{l}\text { Determine if education } \\
\text { regarding food insecurity as a } \\
\text { health issue could modify } \\
\text { knowledge, attitudes, and } \\
\text { clinical behavior. Educational } \\
\text { sessions on food insecurity } \\
\text { and its impact on health were } \\
\text { conducted with faculty, } \\
\text { residents, and medical } \\
\text { students at } 3 \text { different family } \\
\text { medicine residency programs } \\
\text { and } 1 \text { medical school. }\end{array}$ & $\begin{array}{l}\text { Study design: Presurveys/ } \\
\text { postsurveys and EHR review } \\
\text { Sample: } 51 \text { medical students, } 29 \\
\text { residents, and } 5 \text { faculty } \\
\text { members } \\
\text { Setting: } 3 \text { family medicine } \\
\text { residency programs and } 1 \\
\text { medical school }\end{array}$ \\
\hline
\end{tabular}
curriculum sustained more positive attitudes toward community pediatrics, child advocacy, and caring for vulnerable populations than the categorical residents, whose attitudes significantly decreased. CHAT residents indicated that topics such as child welfare, community violence, accessing community resources for underserved children and children with special health care needs, and providing preventive health education to various community groups such as schools and child care facilities were important to the primary care of children.

Knowledge: Participants reported sustained increased knowledge of importance and relevance of food insecurity and food resources.

Attitudes/Beliefs: All participants endorsed the importance of assessing and referring patients for food resources preintervention. These scores increased postintervention as well as willingness to ask patients about food insecurity. 


\begin{tabular}{ccc}
\hline Author, Year & $\begin{array}{l}\text { Target Social } \\
\text { Need(s) }\end{array}$ & Objective \\
\hline & Health literacy & $\begin{array}{l}\text { Evaluate the effects of a health } \\
\text { literacy training intervention } \\
\text { for the entire staff of one } \\
\text { family medicine residency } \\
\text { promer, } \\
\text { polegram clinic. }\end{array}$ \\
\hline
\end{tabular}

$\begin{aligned} & \text { Stikes et al, } \\ & 2015^{57}\end{aligned}$

Primack, et al. Health literacy
$2007^{47}$

Nonintervention studies $(\mathrm{n}=17)$

$\begin{array}{cc}\begin{array}{c}\text { De Marchis et } \\ \text { al, } 2019^{77}\end{array} & \text { Multiple social } \\ \text { needs }\end{array}$

Garg et al, $2019^{76}$
Describe how participation in leadership academy positioned the authors to lead an interdisciplinary team through implementation and evaluation of a change project related to patient education based upon national health literacy standards.

Evaluate impact of educational intervention to improve knowledge of principles of social marketing, knowledge of health literacy, and comfort developing patient education materials.

Examine associations between clinic capacity to address provider burnout.

Assess pediatricians' routine screening practices of lowincome families for social needs, attitudes toward screening, and referral of lowincome families for community resources. patients' social needs and

Provider Assessment Study

Design, Target Population and Setting

Provider-Related Outcomes

Study design: Presurveys/ postsurveys

Sample: Physicians $(\mathrm{n}=11)$ nonphysicians (34)

Setting: Family medicine residency
Study design: Quality improvement project Sample/Setting: Mother/baby unit of an academic medical center serving a high percentage of patients of a minority population and underserved clients

Study design: Precomparison/ postcomparison Sample: 83 medical students Setting: Medical school

Study design: Cross-sectional survey

Sample: 1298 family physicians

Setting: Primary care

Study design: Analysis of data from the American Academy of Pediatrics Periodic Survey from October 2014 to March 2015Sample: 603 pediatricians Setting: Pediatric care
Behavior: Increased discussion of food insecurity during clinical visits and referrals to food resources.

Knowledge: Overall, participants reported an increase in selfperceived health literacy knowledge \& skills. Physicians with more experience were more likely to report improved knowledge, including understanding what it means for patients to have low health literacy (6.83 versus 6.0, $P=.03$ ) and knowing the prevalence of low health literacy (6.83 versus $6.2, P=.04$.)

Behavior: More experienced physicians were more likely to report improved intended behaviors: paying attention to whether patients are understanding them (6.83 versus $6.2, P=.03)$ and creating a shame-free environment (6.8 versus 6.2, $P=.04$ ).

Knowledge: Increased direct care nurses' knowledge of health literacy interventions.

Behavior: Increased competency on use of updated patient education materials and adoption of health literacy interventions.

Knowledge: Postintervention scores were significantly higher than preintervention scores for health literacy.

Attitudes/Beliefs: Physicians who perceived their clinic as having a high capacity to address patients' social needs were less likely to report burnout.

Attitudes/Beliefs: Most pediatricians reported that social risk screening is important; fewer reported that screening is feasible or felt prepared addressing families' social needs.

Behavior: More than half of pediatricians reported routinely screening for at least 1 social need. Pediatricians were more likely to report that they screen and refer when having more patients in financial hardship and/or having someone in the practice assigned the responsibility of connecting low-income families to community services. 


\begin{tabular}{|c|c|c|c|c|}
\hline Author, Year & $\begin{array}{l}\text { Target Social } \\
\text { Need(s) }\end{array}$ & Objective & $\begin{array}{l}\text { Provider Assessment Study } \\
\text { Design, Target Population and } \\
\text { Setting }\end{array}$ & Provider-Related Outcomes \\
\hline $\begin{array}{l}\text { Pantell et al, } \\
2019^{65}\end{array}$ & $\begin{array}{l}\text { Multiple social } \\
\text { needs }\end{array}$ & $\begin{array}{l}\text { Examine associations between } \\
\text { clinic capacity to respond to } \\
\text { patients' social needs and } \\
\text { physician satisfaction, stress, } \\
\text { and perceived medical care } \\
\text { quality. }\end{array}$ & $\begin{array}{l}\text { Study design: Cross-sectional } \\
\text { survey } \\
\text { Sample: } 890 \text { primary care } \\
\text { physiciansSetting: Primary } \\
\text { Care }\end{array}$ & $\begin{array}{l}\text { Attitudes/Beliefs: Physicians who } \\
\text { reported practicing in a clinic they } \\
\text { felt was prepared to manage } \\
\text { patients with social needs had } \\
\text { higher job satisfaction; were more } \\
\text { satisfied with amount of time spent } \\
\text { with patients; and were more likely } \\
\text { to think that the quality of medical } \\
\text { care patients receive had improved. }\end{array}$ \\
\hline $\begin{array}{l}\text { Schickedanz et } \\
\text { al., } 2019^{75}\end{array}$ & $\begin{array}{l}\text { Multiple social } \\
\text { needs }\end{array}$ & $\begin{array}{l}\text { Describe the attitudes and } \\
\text { experiences of social needs } \\
\text { screening among clinicians } \\
\text { and other health care } \\
\text { professionals. }\end{array}$ & $\begin{array}{l}\text { Study design: Multicenter cross- } \\
\text { sectional survey } \\
\text { Sample: } 154 \text { physicians, } 104 \\
\text { nonphysicians (eg, social } \\
\text { workers, nurses, and } \\
\text { pharmacists) } \\
\text { Setting: Large integrated medical } \\
\text { system }\end{array}$ & $\begin{array}{l}\text { Knowledge: Nonphysician } \\
\text { respondents ( } \mathrm{n}=104) \text { were more } \\
\text { likely than physician respondents } \\
\text { (154) to be aware of relevant } \\
\text { socioeconomic resources ( } 64 \% \text { vs } \\
45 \%, P=0.03 \text { ) and to think social } \\
\text { needs were an issue for patients } \\
\text { ( } 90.3 \% \text { vs } 76.4 \%, P=0.02) \text {. } \\
\text { Attitudes/Beliefs: Most health } \\
\text { professionals surveyed agreed that } \\
\text { social needs screening should be a } \\
\text { standard part of clinical care. } \\
\text { Barriers to screening included lack } \\
\text { of time and lack of resources to } \\
\text { address patients' needs. Less than } \\
\text { half felt confident in their ability to } \\
\text { address social needs. Social workers } \\
\text { and case managers were most often } \\
\text { identified as best suited to screen } \\
\text { for and address social needs. } \\
\text { Behavior: One in } 5 \text { clinician } \\
\text { respondents indicated that they } \\
\text { always ask patients about their } \\
\text { social needs. Thirty-five percent } \\
\text { reported using information about } \\
\text { patients' social needs in medical } \\
\text { management. }\end{array}$ \\
\hline $\begin{array}{l}\text { Olayiwola et al, } \\
2018^{61}\end{array}$ & $\begin{array}{l}\text { Multiple social } \\
\text { needs }\end{array}$ & $\begin{array}{l}\text { Explore the relationship between } \\
\text { provider burnout and clinic } \\
\text { capacity to address patient } \\
\text { social needs. }\end{array}$ & $\begin{array}{l}\text { Study design: Cross-sectional } \\
\text { survey } \\
\text { Sample: } 359 \text { primary care } \\
\text { providers } \\
\text { Setting: } 3 \text { urban health care } \\
\text { delivery systems }\end{array}$ & $\begin{array}{l}\text { Attitudes/Beliefs: Providers reported it } \\
\text { was important to address patient } \\
\text { social needs in primary care and } \\
\text { high levels of confidence in asking } \\
\text { patients about their social needs. } \\
\text { Providers were less confident in } \\
\text { their skills and available clinic } \\
\text { resources to address social needs. } \\
\text { Providers' strong beliefs in the } \\
\text { importance of addressing social } \\
\text { needs, higher comfort asking about } \\
\text { social needs, and greater skills } \\
\text { addressing social needs were } \\
\text { significantly associated with lower } \\
\text { reported levels of exhaustion and } \\
\text { cynicism and higher levels of } \\
\text { professional efficacy }\end{array}$ \\
\hline $\begin{array}{l}\text { Palacio et al, } \\
2018^{62}\end{array}$ & $\begin{array}{l}\text { Multiple social } \\
\text { needs }\end{array}$ & $\begin{array}{l}\text { Understand differences in } \\
\text { provider perspectives and } \\
\text { preferences around collecting } \\
\text { social determinants of health } \\
\text { data according to provider } \\
\text { characteristics. }\end{array}$ & $\begin{array}{l}\text { Study design: Cross-sectional } \\
\text { survey } \\
\text { Sample: } 240 \text { clinical faculty } \\
\text { Setting: Medical school }\end{array}$ & $\begin{array}{l}\text { Attitudes/Beliefs: The majority of } \\
\text { participants agreed that SDoH are } \\
\text { important predictors of health } \\
\text { outcomes and care quality }(83 \%) \text {. } \\
\text { A greater number of females } \\
\text { compared to males agreed that } \\
\text { SDoH collection would enable } \\
\text { development of special programs } \\
\text { for at-risk populations. } 72 \% \text { of } \\
\text { participants agreed that collecting }\end{array}$ \\
\hline
\end{tabular}

Continued 


\begin{tabular}{llll}
\hline & & & Provider Assessment Study \\
& Target Social & & Design, Target Population and \\
Author, Year & Need(s) & Objective & Setting
\end{tabular}

$\begin{array}{cc}\begin{array}{c}\text { Purnell et al, } \\ 2018^{66}\end{array} & \begin{array}{c}\text { Multiple social } \\ \text { needs }\end{array} \\ & \begin{array}{c}\text { Assess provider perceptions of } \\ \text { their organization's cultural } \\ \text { competence climate and their } \\ \text { skills and behaviors targeting } \\ \text { patient-centered care for }\end{array} \\ & \text { culturally and socially diverse } \\ \text { patients }\end{array}$

Robinson et al, Multiple social Assess perceptions on the $2018^{67}$ needs emergency department's (ED's) role in providing social support.
Study design: Cross-sectional survey

Sample: 1220 faculty, fellows, and resident physicians

Setting: Academic health care system
Study design: Cross-sectional survey

Sample: 39 physicians, 43 nurses, and 32 other ED staff

Setting: 2 urban pediatric EDs

\begin{tabular}{|c|c|c|}
\hline $\begin{array}{c}\text { Lewis et al, } \\
2016^{68}\end{array}$ & $\begin{array}{l}\text { Multiple social } \\
\text { needs }\end{array}$ & $\begin{array}{l}\text { Evaluate provider ability to } \\
\text { identify, treat, and code for } \\
\text { SDoH. Providers completed } \\
\text { surveys to assess perceptions } \\
\text { of SDoH and their ability to } \\
\text { address them. Then providers } \\
\text { filled out } 1 \text { anonymous card } \\
\text { per patient documenting } \\
\text { social factors observed during } \\
\text { encounters. }\end{array}$ \\
\hline
\end{tabular}

Study design: Descriptive analysis of provider surveys and documentation of screening practices

Sample: 43 primary care providers

Setting: 3 CHC organizations
SDoH information would put additional burden on providers; $58 \%$ thought the benefit of this information would outweigh the burden. Belonging to a racial ethnic minority group was associated with believing that benefits of collecting SDoH outweigh the risks. The most common concern cited by providers was inadequate resources to address social needs. Among minority physicians, the secondmost common concern was liability related to not addressing a risk leading to an adverse outcome, whereas for nonminority faculty and specialists, it was not knowing how to use SDoH data once they are available. More than half of participants thought primary care providers should be responsible for managing social risk factors.

Attitudes/Beliefs: Providers who perceived major structural problems within their own clinic's organizational climate felt less skilled in identifying patient mistrust, patients' English literacy, and socioeconomic barriers. Respondents reported poor access to interpreters and lack of time to address cultural barriers as challenges to care delivery.

Behavior: Respondents who perceived more structural problems were more likely to report that they infrequently act to adapt services to patient and family cultural preferences.

Attitudes/Beliefs: Most ED staff felt knowing information about families' home social resources would help patient care and should be addressed. Food insecurity and transportation issues were most widely accepted by staff. Significantly fewer nursing staff members compared with physicians felt comfortable asking patients about child care needs.

Knowledge: Providers reported familiarity with SDoH concepts.

Attitudes/Beliefs: Providers agreed that $\mathrm{SDoH}$ contribute to the health of their patients and were comfortable with identifying $\mathrm{SDoH}$ at the point of care. Most providers were neutral on whether their CHC had adequate resources to address $\mathrm{SDoH}$.

Behavior: A total of 747 cards were completed. 1584 factors were 


\begin{tabular}{|c|c|c|c|}
\hline Author, Year & $\begin{array}{l}\text { Target Social } \\
\text { Need(s) }\end{array}$ & Objective & $\begin{array}{l}\text { Provider Assessment Study } \\
\text { Design, Target Population and } \\
\text { Setting }\end{array}$ \\
\hline $\begin{array}{l}\text { Losonczy et al, } \\
2015^{63}\end{array}$ & $\begin{array}{l}\text { Multiple social } \\
\text { needs }\end{array}$ & $\begin{array}{l}\text { Explore emergency department } \\
\text { (ED) providers' perceptions of } \\
\text { health-related social issues } \\
\text { facing their patients. }\end{array}$ & $\begin{array}{l}\text { Study design: Cross-sectional } \\
\text { survey } \\
\text { Sample: } 432 \text { ED physicians and } \\
\text { residents } \\
\text { Setting: } 79 \text { emergency medicine } \\
\text { training programs }\end{array}$ \\
\hline
\end{tabular}

\begin{tabular}{|c|c|c|c|c|}
\hline $\begin{array}{l}\text { O'Toole et al, } \\
2012^{74}\end{array}$ & $\begin{array}{l}\text { Multiple social } \\
\text { needs }\end{array}$ & $\begin{array}{l}\text { To examine the effects of clinic- } \\
\text { based social and legal } \\
\text { resources on resident } \\
\text { knowledge and screening } \\
\text { patterns for social } \\
\text { determinants of health. }\end{array}$ & $\begin{array}{l}\text { Study design: Cross-sectional } \\
\text { comparative analysis } \\
\text { Sample: } 40 \text { pediatric residents } \\
\text { Setting: } 3 \text { continuity clinics }\end{array}$ & $\begin{array}{l}\text { Attitudes/Beliefs: Residents from } \\
\text { clinics with more social and legal } \\
\text { resources reported feeling more } \\
\text { confident in their knowledge about } \\
\text { food security benefits. } \\
\text { Behavior: Residents from clinics with } \\
\text { more social and legal resources } \\
\text { screened more frequently and spent } \\
\text { more time taking social histories. }\end{array}$ \\
\hline $\begin{array}{c}\text { Garg et al, } \\
2009^{73}\end{array}$ & $\begin{array}{l}\text { Multiple social } \\
\text { needs }\end{array}$ & $\begin{array}{l}\text { Examine resident providers' } \\
\text { attitudes and behaviors toward } \\
\text { addressing parent-reported } \\
\text { social needs. }\end{array}$ & $\begin{array}{l}\text { Study design: Cross-sectional } \\
\text { survey } \\
\text { Sample: } 45 \text { pediatric residents } \\
\text { Setting: Pediatric primary care }\end{array}$ & $\begin{array}{l}\text { Attitudes/Beliefs: The majority of } \\
\text { resident providers believed in the } \\
\text { importance of addressing social needs } \\
\text { and felt responsible for screening. } \\
\text { Behavior: Few providers reported } \\
\text { routinely screening for these needs } \\
\text { (range, } 11 \% \text { to } 18 \% \text { ). }\end{array}$ \\
\hline $\begin{array}{l}\text { Grindler et al, } \\
2018^{64}\end{array}$ & $\begin{array}{l}\text { Prenatal enviro- } \\
\text { nmental } \\
\text { exposures }\end{array}$ & $\begin{array}{l}\text { Determine the frequency of } \\
\text { environmental exposure } \\
\text { screening by obstetricians and } \\
\text { gynecologists (OBGYNs) at } \\
\text { initial patient visits. }\end{array}$ & $\begin{array}{l}\text { Study design: Cross-sectional } \\
\text { surveys } \\
\text { Sample: } 312 \text { practicing OBGYNs } \\
\text { Setting: National survey of } \\
\text { practicing OBGYNs }\end{array}$ & $\begin{array}{l}\text { Knowledge: The majority of OBGYNs } \\
\text { reported that they did not know how } \\
\text { to reduce adverse environmental } \\
\text { exposures or have the knowledge to } \\
\text { advise patients about associations } \\
\text { between environmental chemicals } \\
\text { and health. } \\
\text { Attitudes/Beliefs: Providers did not feel } \\
\text { comfortable obtaining an } \\
\text { environmental history. } \\
\text { Behavior: Fewer than half of physicians } \\
\text { screened for the environmental } \\
\text { exposures. }\end{array}$ \\
\hline $\begin{array}{c}\text { Pooler, et al. } \\
2018^{69}\end{array}$ & Food insecurity & $\begin{array}{l}\text { Explore the beliefs of primary } \\
\text { care providers (PCPs) about } \\
\text { food security screening and } \\
\text { referrals in a primary care } \\
\text { setting and perceived barriers } \\
\text { to implementation. }\end{array}$ & $\begin{array}{l}\text { Study design: Qualitative } \\
\text { semistructured interviews } \\
\text { Sample: } 16 \text { health care providers } \\
\text { (physicians, nurse } \\
\text { practitioners, physician } \\
\text { assistants) } \\
\text { Setting: Primary care }\end{array}$ & $\begin{array}{l}\text { Knowledge: More than half of the } \\
\text { PCPs expressed a desire to know } \\
\text { about more resources for patients. } \\
\text { Attitudes/Beliefs: PCPs supported } \\
\text { implementing food security } \\
\text { screening and referrals in their } \\
\text { practices. PCPs expressed a variety }\end{array}$ \\
\hline
\end{tabular}

Provider-Related Outcomes

identified, and $31 \%$ were reported as having a service provided.

Knowledge: Providers reported believing that social needs caused patients to return to the ED. Most providers expressed a desire for more resources to address social needs and reported they would attend related educational sessions.

Attitudes/Beliefs: Fewer than 1\% of respondents replied that addressing nonmedical needs was not part of their job or that such needs were not relevant to patients' health. Reported barriers to screening included feeling unable to act, lack of time, and lack of knowledge.

Behavior: Provider screening rates were dependent on specific need, ranging from $61 \%$ to $100 \%$ of visits. Providers referred to social workers, outside agencies, and/or tried to solve identified problems themselves.

Attitudes/Beliefs: Residents from clinics with more social and legal resources reported feeling more confident in their knowledge about food security benefits. screened more frequently and spent titudes/Beliefs: The majority of resident providers believed in the importance of addressing social needs and felt responsible for screening. routinely screening for these needs $18 \%$

reported that they did not know how to reduce adverse environmental and health.

comfortable obtaining an environmental history. screened for the environmenta PCPs expressed a desire to know Attitudes/Beliefs: PCPs supported implementing food security practices. PCPs expressed a variety 


\begin{tabular}{llll}
\hline & & & Provider Assessment Study \\
& Target Social & & Design, Target Population and \\
Author, Year & Need(s) & Objective & Setting
\end{tabular}

Barnidge et al, Food insecurity Assess provider readiness to $2017^{72}$

Hoisington et al, Food insecurity $2012^{70}$

Cafiero, $2013^{71} \quad$ Health literacy Assess the knowledge, experience, and intention of nurse practitioners (NPs) to use health literacy strategies in in clinical practice. to examine factors that influence FI monitoring.
Study design: Cross-sectional survey

Sample: 67 physicians screenings, and barriers to conducting those screenings.

Setting: Pediatrics
Study design: Cross-sectional survey

Sample: 186 family practice pediatric nurse practitioners and physicians

Setting: Pediatric primary care

of concerns and challenges including competing screenings, competing demands from a business perspective, and adequate time and resources available for referrals. PCPs suggested support staff could screen and refer patients.

Behavior: Screening frequencies for food insecurity varied. PCPs often discussed access to food in the context of existing chronic conditions.

Knowledge: The majority of physicians believed that $\mathrm{FI}$ is a challenge for their patients.

Attitudes/Beliefs: Most pediatricians were willing to screen patients for FI. Concerns included uncertainty about how to handle a positive screen, lack of knowledge of community resources, that caregivers will feel judged, time needed to screen, comfort with screening, reduced patient satisfaction, and uncertainty about reimbursement for screening. Emergency and specialty providers felt ill equipped to respond to FI and that FI screening was not an appropriate use of time in these settings.

Behavior: $15 \%$ of pediatricians said they currently screen for FI.

Knowledge: Few providers considered themselves very knowledgeable about FI and FI prevalence.

Attitudes/Beliefs: Most providers were willing to use a standardized screening question, and $2.8 \%$ felt FI should not be discussed in a clinical setting. Providers identified time constraints, lack of resources, inadequate knowledge, and concerns about question sensitivity as barriers to screening.

Behavior: Most respondents did not routinely inquire about household FI during clinic visits. Monitoring of household food nutritional quality was predicted by providers' time availability and years in practice.

Study design: Cross-sectional survey

Sample: 256 outpatient care NPs Setting: National NP education conference

Knowledge: The majority of NPs were aware of the consequences of health literacy and guidelines for written materials.

Behavior: Intention to use health literacy strategies in clinical practice with patients was high. NPs reported using few health literacy strategies in practice and rates of health literacy assessments varied.

*See article references for study citations.

CHC, community health center; CHW, community health worker; EHR, electronic health record; HPACT, Homeless Patient Aligned Care Team; MA, medical assistant; RCT, randomized controlled trial; RN, registered nurse; SDoH, social determinants of health. 